\title{
GEOSCIENCE/ENGINEERING CHARACTERIZATION OF THE
}

INTERWELL ENVIRONMENT IN CARBONATE RESERVOIRS BASED ON OUTCROP ANALOGS, PERMIAN BASIN, WEST TEXAS AND NEW MEXICO - PETROPHYSICAL CHARACTERIZATION OF THE SOUTH COWDEN GRAYBURG RESERVOIR, ECTOR COUNTY, TEXAS

Final Report

By

F. Jerry Lucia

$$
\text { RECEIVED }
$$

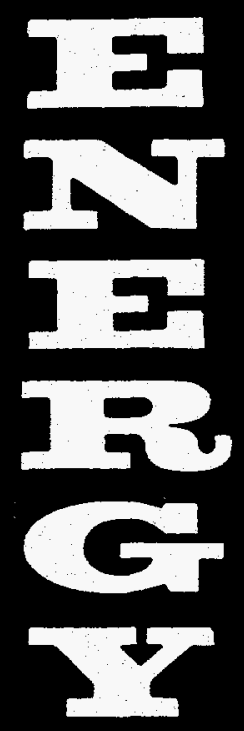

June 1997

\section{JUN 10997}

OSTI

Performed Under Contract No. DE-AC22-93BC14895

The University of Texas at Austin

Austin, Texas

\section{National Petroleum Technology Office U. S. DEPARTMENT OF ENERGY Tulsa, Oklahoma}




\section{DISCLAIMER}

This report was prepared as an account of work sponsored by an agency of the United States Government. Neither the United States Govemment nor any agency thereof, nor any of their employees, makes any warranty, expressed or implied, or assumes any legal liability or responsibility for the accuracy, completeness, or usefulness of any information, apparatus, product, or process disclosed, or represents that its use would not infringe privately owned rights. Reference herein to any specific commercial product, process, or service by trade name, trademark, manufacturer, or otherwise does not necessarily constitute or imply its endorsement, recommendation, or favoring by the United States Government or any agency thereof. The views and opinions of authors expressed herein do not necessarily state or reflect those of the United States Government.

This report has been reproduced directly from the best available copy.

Available to DOE and DOE contractors from the Office of Scientific and Technical Information, P.O. Box 62, Oak Ridge, TN 37831; prices available from (615) 5768401.

Available to the public from the National Technical Information Service, U.S. Department of Commerce, 5285 Port Royal Rd., Springfield VA 22161 
DOE/BC/14895-13 (Vol II)

Distribution Category UC-122

Geoscience/Engineering Characterization Of The Interwell Environment In Carbonate Reservoirs Based On Outcrop Analogs, Permian Basin, West Texas And New Mexico - Petrophysical Characterization Of The South Cowden Grayburg Reservoir, Ector County, Texas

Final Report

\author{
By \\ F. Jerry Lucia
}

June 1997

Work Performed Under Contract No. DE-AC22-93BC14895

\author{
Prepared for \\ U.S. Department of Energy \\ Assistant Secretary for Fossil Energy
}

Robert E. Lemmon, Project Manager

National Petroleum Technology Office

P.O. Box 3628

Tulsa, OK 74101

Prepared by:

The University of Texas at Austin

Bureau of Economic Geology

Austin, Texas 78713-8924 



\section{DISCLAMMER}

Portions of this document may be illegible in electronic image products. Images are produced from the best available original document. 



\section{CONTENTS}

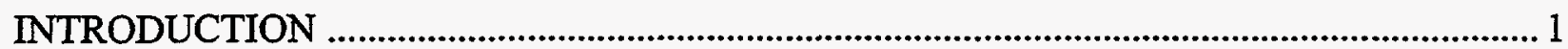

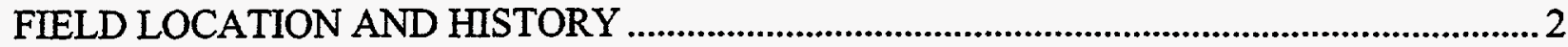

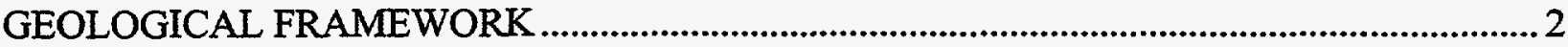

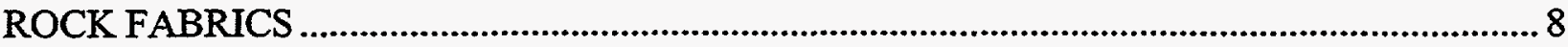

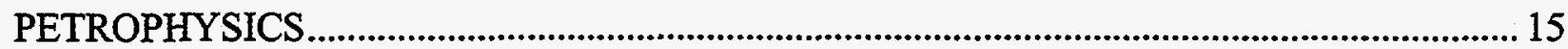

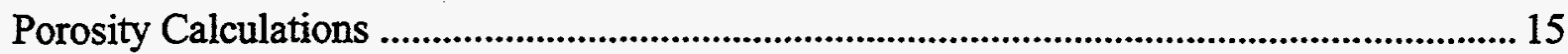

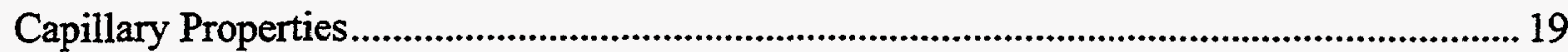

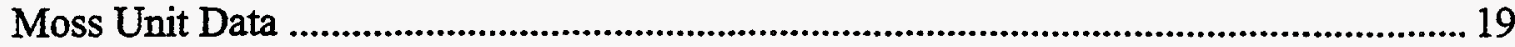

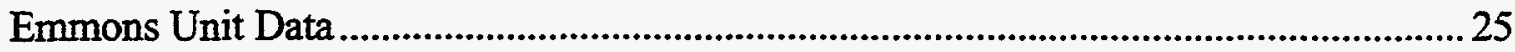

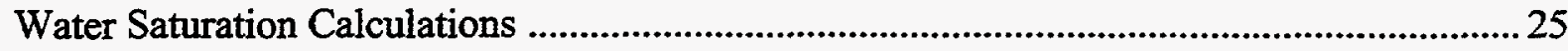

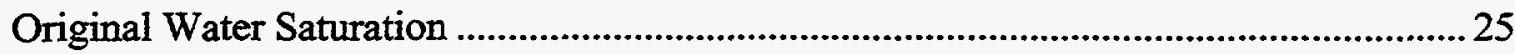

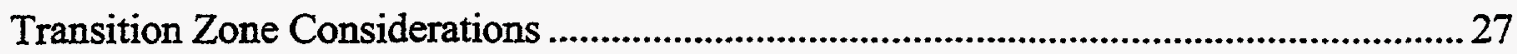

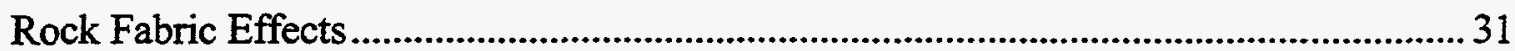

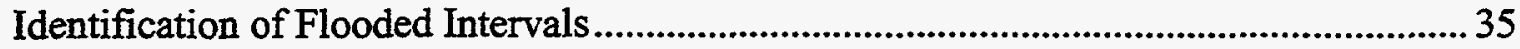

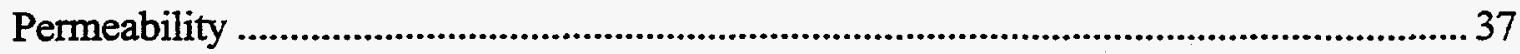

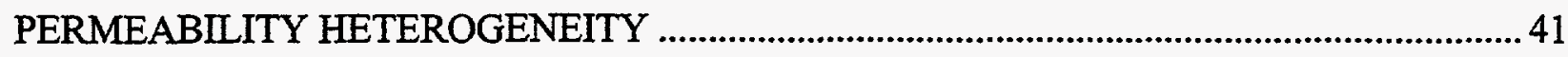

LOCATION OF REMAINING MOBILE OIL .............................................................47

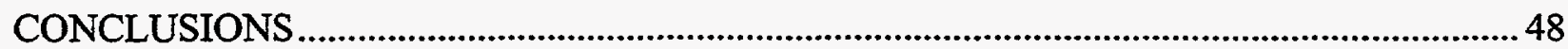

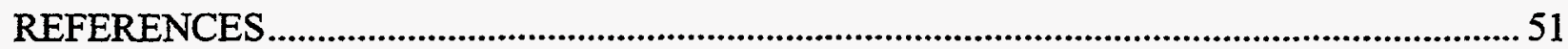

Figures

1. Structure map of South Cowden field showing production units and study area ................ 3

2. Isopach map of the cumulative production from original development wells in the study area.... 
3. East-west structural cross section of South Cowden reservoir showing the distribution of permeability and anhydrite alteration types

4. Stratigraphic cross section of South Cowden field showing high-frequency sequences and cycles

5. Core descriptions from wells Moss Unit 16-14 and Emmons Unit 143 showing sequences and high-frequency cycles

6. Examples of cycle correlations using gamma-ray logs showing good upward-shallowing cycles in highstand tracts

7. Diagram illustration South Cowden rock-fabric/petrophysical classes 10

8. Photomicrographs of petrophysical fabric showing Class 1 dolograinstone, Class 1 large crystalline grain-dominated dolostone, Class 2 grain-dominated dolopackstone, and Class 2 medium crystalline dolowackestone

9. Photomicrographs of petrophysical fabrics showing Class 2, poorly sorted dolomite crystals in a dolowackestone, and Class 3 , poorly sorted dolomite crystals in a dolowackestone

10. Photographs of petrophysical fabrics: photomicrograph of fusumolds and microfractures occluded by anhydrite; photomicrographs of fusumolds connected by microfractures; and core photo of a vug formed by dissolution of an anhydrite nodule.

11. Cross plot of core porosity and open-hole neutron log porosity values for seven wells .... 16

12. Cross plot of core porosity and cased-hole neutron porosity values for three wells 16

13. Comparison of average porosity values in the reservoir interval from the five cased-hole logging companies

14. Cross plot of neutron-density porosity and acoustic traveltime showing distinct porosity transforms for each of three rock fabrics

15. Map showing distribution of rock fabrics based on acoustic porosity cross plots. 20

16. Capillary pressure graphs for three grainstones of varying porosity from the Moss Unit.. 22

17. Petrophysical class 2 average capillary-pressure curves for three porosity groups compared with curves calculated from the class 2 saturation model using identical porosity values

18. Petrophysical class 3 average capillary-pressure curves from three porosity groups compared with curves calculated from the saturation model using identical porosity values

19. Comparison of capillary properties from the three petrophysical classes at similar porosity values

20. Capillary-pressure curves from class 2 , touching-vug fabric, acoustic group 3 , Emmons Unit 142 
21. Capillary-pressure curves from altered sulfate fabric, acoustic group 2, Emmons Unit 143

22. Cross plot of porosity and log calculated water saturation from Moss Unit 8-12 showing water saturation-porosity transform used to calculate original water saturation above the transition zone

23. Comparison of capillary-pressure saturation model using a reservoir height of $350 \mathrm{ft}$ with the saturation transform from Moss Unit 8-12

24. Diagrammatic illustration of capillary-pressure curves for petrophysical class 2 with 10 percent porosity illustrating the difference in saturation values between drainage and imbibition curves

25. Illustration of the effect of tilting and remigration on saturation profiles resulting from imbibition considerations

26. Comparison of imbibition and drainage-saturation models in the updip (west) and downdip (east) locations using the class 2 capillary-pressure model and 10 percent porosity

27. Cross plots of porosity, water saturation, and rock fabric for the $G$ interval 33

28. A portion of Moss Unit 17-22 well illustrating how rock fabric can be interpreted from saturation considerations.

29. Illustration of flooded and unflooded intervals in the Moss Unit 8-8wr well, a replacement well for the 8-8w water injection well completed in 1965

30. Porosity and permeability data from Moss Unit 6-16 core analysis data compared with the generic class 2 porosity-permeability transform of Lucia (1995).

31. Porosity-permeability cross plot of core data from the interval $4800-4900$ in Moss Unit 6-20, Emmons Unit 135, and Emmons Unit 136

32. Depth-permeability plot comparing the permeability profile using the class 2 transform only with a profile that incorporates three rock-fabric-specific transforms.

33. Isopach map of permeability-feet (kh) in the reservoir interval (E to -1850) of the study area.

34. Cross section in Moss Unit tracts 16 and 20 illustrating the general conformance of the flow units with high-frequency cycles in the area of unaltered to altered anhydrite

35. Detailed $\mathrm{Kh}$ maps of four high-frequency cycles in the altered and unaltered areas...........44

36. Cross section in the Emmons Unit illustrating the lack of conformance between flow units and high-frequency cycles in the area of anhydrite dissolution.

37. Isopach map of permeability-feet (kh) values from cycle Ex-Eo in HFS 4b showing local permeability development interpreted to result from dissolution of pore-filling anhydrite in a grainstone body

38. Illustrations of altered anhydrite facies within the dissolved anhydrite facies 
39. Cross section of recent infill wells showing (1) flooded zones are adjacent to injection intervals (Moss Unit 20-12), and (2) unflooded zones are below injection depths and where upper pay zones are not well developed (Moss Unit 20-13)

\section{Tables}

1. Wireline logs available in South Cowden field study area ................................................... 15

2. Parameter used in converting capillary-pressure data into reservoir height ........................20

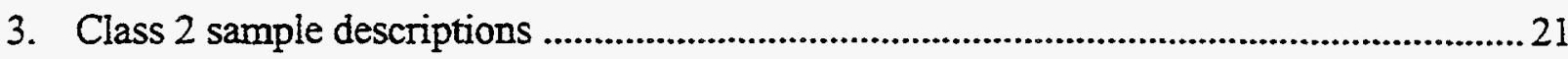

4. Average porosity for Class 2 porosity groups ........................................................................21

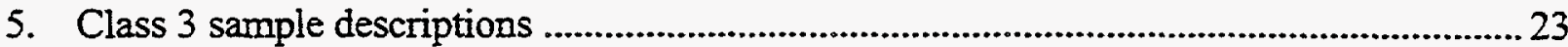

6. Average porosity for Class 3 porosity groups............................................................................23 


\section{INTRODUCTION}

Reservoir performance of the South Cowden Grayburg field suggests that only 21 percent of the original oil in place has been recovered. The purpose of this study is to construct a realistic reservoir model to be used to predict the location of the remaining mobile oil. Construction of reservoir models for fluid-flow simulation of carbonate reservoirs is difficult because they typically have complicated and unpredictable permeability patterns. Much of the difficulty results from the degree to which diagenetic overprinting masks depositional textures and patterns. For example, the task of constructing a reservoir model of a limestone reservoir that has undergone only cementation and compaction is easier than constructing a model of a karsted reservoir that has undergone cavern formation and collapse as well as cementation and compaction.

The Permian-age carbonate-ramp reservoirs in the Permian Basin, West Texas and New Mexico, are typically anhydritic dolomitized limestone. Because the dolomitization occurred soon after deposition, depositional fabrics and patterns are often retained, and a reservoir model can be constructed using depositional concepts. Recent studies of the San Andres outcrop in the Guadalupe Mountains (Kerans and others, 1994, Grant and others, 1994) and the Seminole San Andres reservoir in the Permian Basin (Lucia and others, 1995) illustrate how depositional fabrics and patterns can be used to construct a reservoir model when depositional features are retained.

The South Cowden field, Ector County, Texas, is a Grayburg (Permian age) anhydritic dolomite reservoir similar to many other Permian reservoirs in the Permian Basin. However, the diagenetic overprint has so advanced that in some parts of the field depositional patterns and fabrics no longer can be used to predict and model permeability. In this paper we develop a reservoir model that includes areas where depositional patterns are useful and areas where they are not useful because diagenetic overprinting masks depositional patterns. 


\section{FIELD LOCATION AND HISTORY}

The South Cowden field is located in Ector County, Texas, at a depth of 4,000-5,000 ft, and it produces from Grayburg dolomites and Queen sandstones. It is part of a complex of fields that includes the Johnson, North Foster, and South Foster fields. This study includes only a part of the South Cowden field, the Moss Unit operated by Unocal, the Emmons Unit operated by Fina, the South Cowden Unit operated by Phillips, and the Colbert Unit currently operated by Aghorn. The study area covers about 14 sections (fig. 1).

The South Cowden field was discovered in 1933, and development was initiated in 1948 with 40-acre-spaced wells. The field was unitized in 1962, and injection wells were drilled in an inverted five-spot pattern. Infill drilling has occurred sporadically. Currently, there is no regular pattern to the waterflood. A reservoir characterization study and pilot $\mathrm{CO}_{2}$ flood are being conducted by Phillips Petroleum Company in the South Cowden Unit funded in part by the U.S. Department of Energy.

A map of cumulative production from original development wells (fig. 2) shows great differences in reservoir quality in the study area. The eastern and southern boundaries of production are related to structural dip, whereas reduced porosity and permeability are the cause of reduced production in the east and north (fig. 3).

\section{GEOLOGICAL FRAMEWORK}

The reservoir geology of the South Cowden field has been described recently by Ruppel and Bebout (1996). They described the sequence stratigraphic framework in terms of four highfrequency sequences (HFS) that range from 50 to $100 \mathrm{ft}$ in thickness (fig. 4). The lower two HFS's document platform flooding and backstepping, HFS 3 documents the maximum flooding event, and HFS 4 documents aggradation and basinward progradation of the platform during sealevel highstand. There is a basinward shift in high-energy facies in the middle of HFS 4 , suggesting another sequence boundary that defines HFS 4A and 4B of Ruppel and Bebout (1996). Thus, 


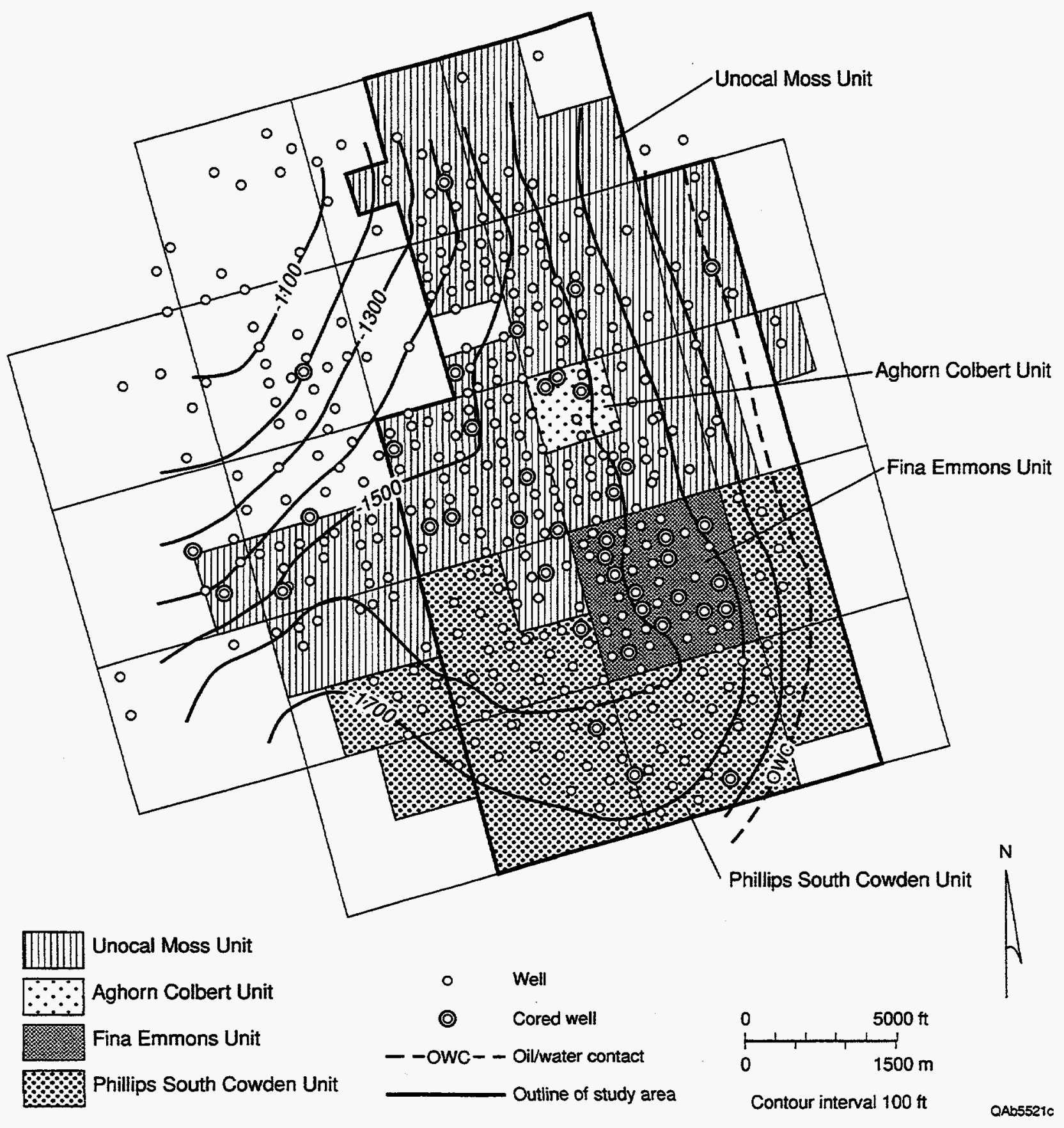

Figure 1. Structure map of South Cowden field showing production units and study area. 


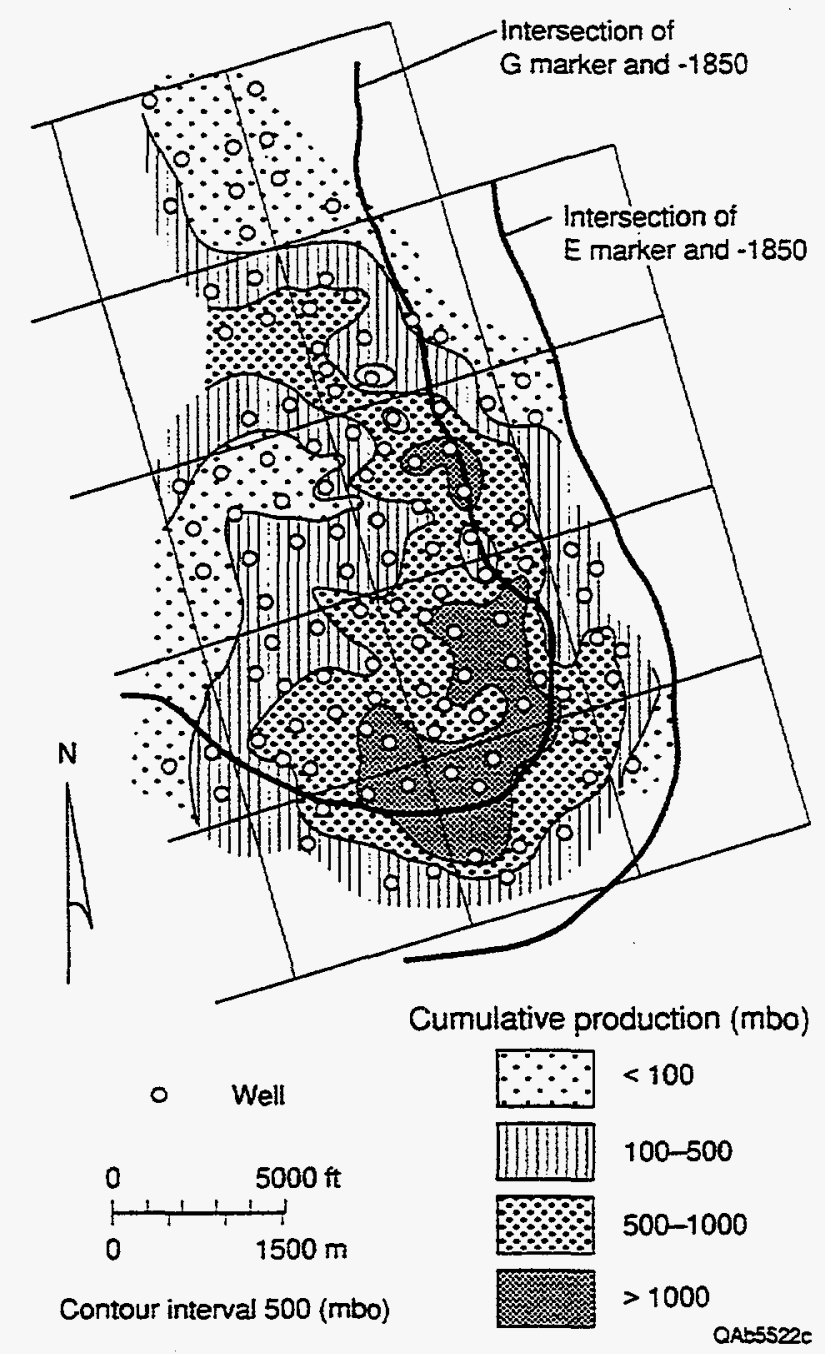

Figure 2. Isopach map of the cumulative production from original development wells in the study area.

the four HFS's form a composite sequence that represents a long-term accommodation cycle, and the facies stacking patterns within the cycles are eustatically controlled.

The South Cowden reservoir is located in HFS's 3 and 4, and these HFS's are divided into chronostratigraphic high-frequency cycles (HFC) to provide a detailed geologic framework suitable for petrophysical quantification (fig. 5). The upper portion of HFS 2, also referred to as the $\mathrm{G}$ interval, is also productive in local areas but has not been divided into HFC's. HFS 3 is composed of three cycles, all containing basal silty carbonate layers (fig. 5). The lower two 


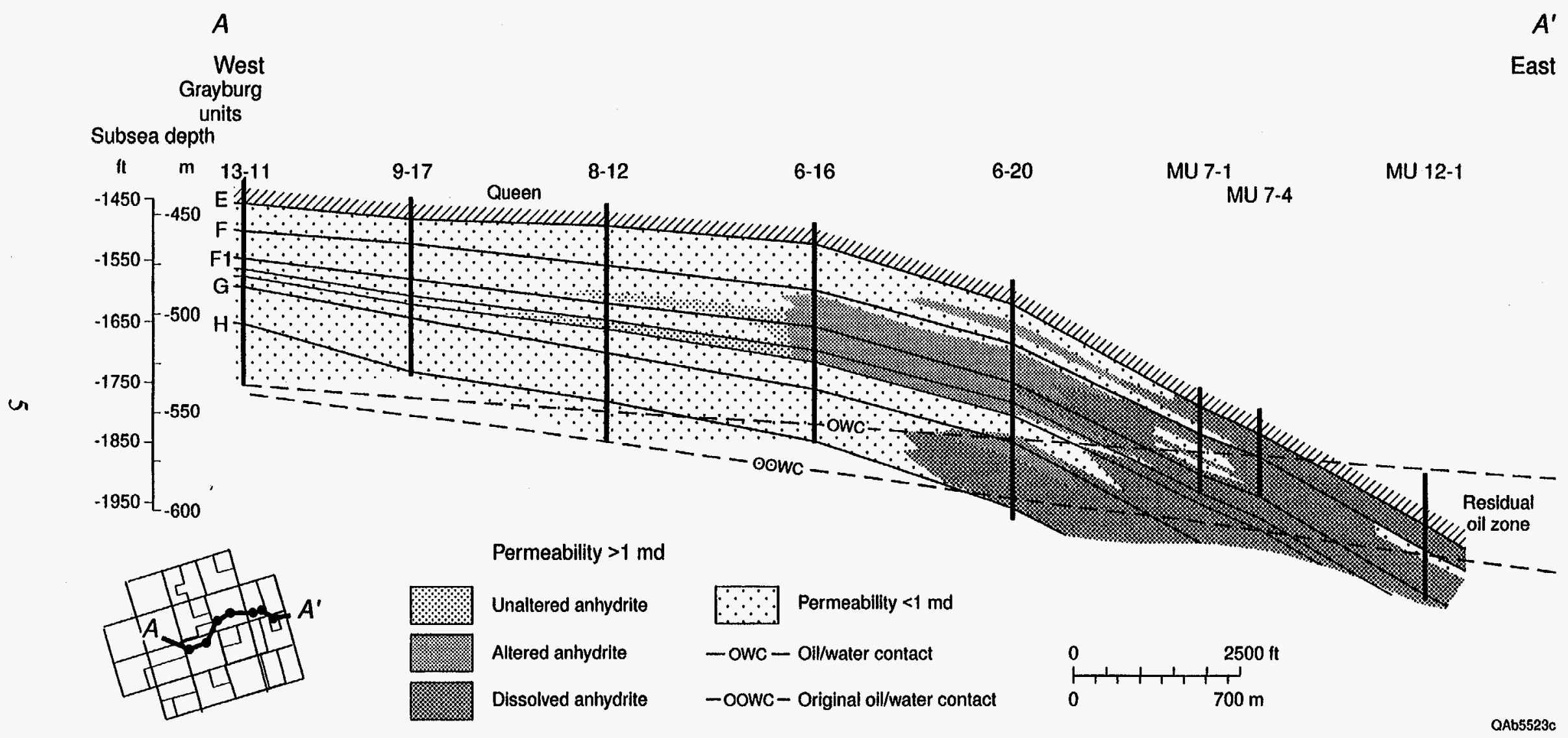

Figure 3. East-west structural cross section of South Cowden reservoir showing the distribution of permeability and anhydrite alteration types. 


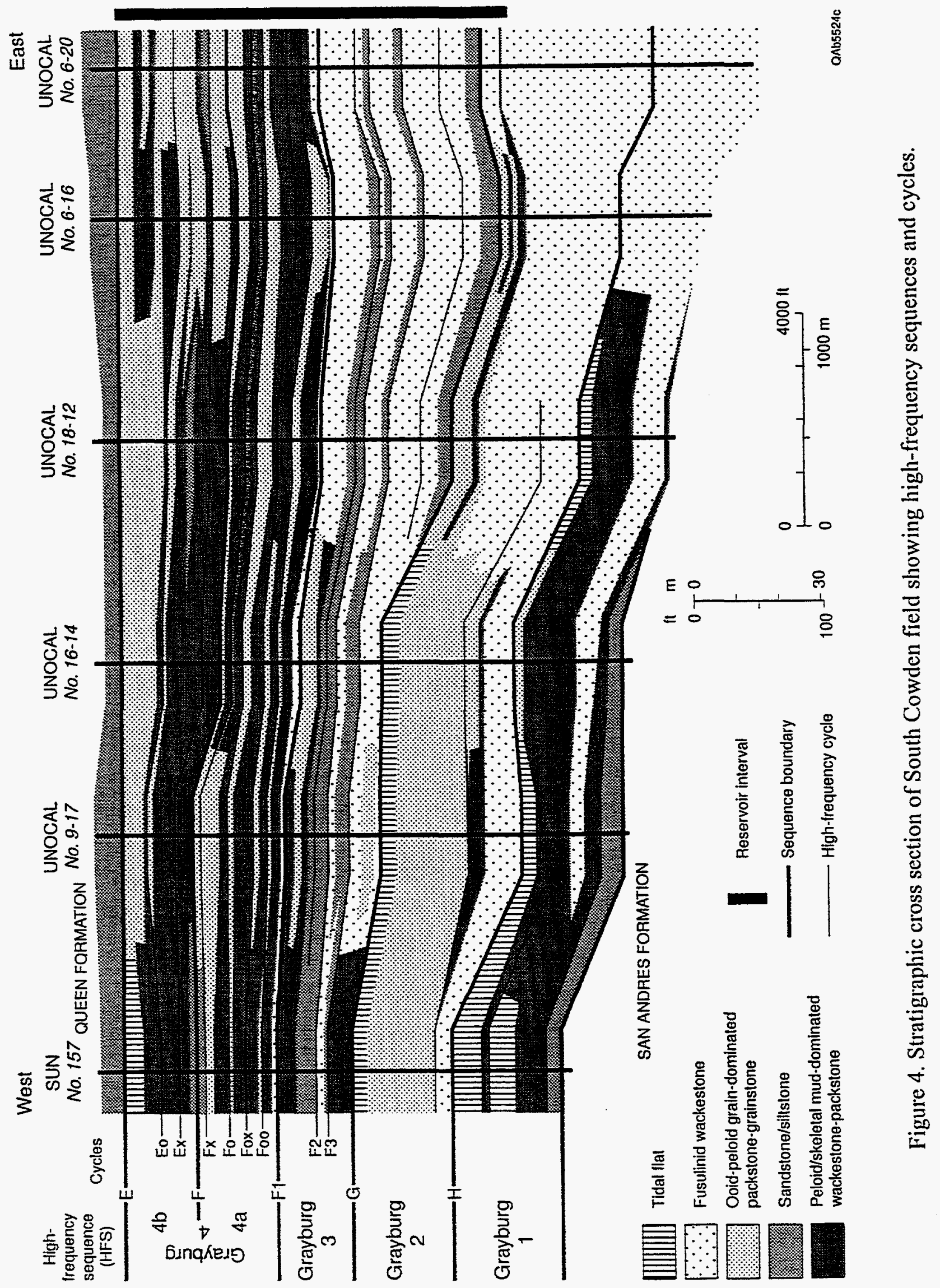




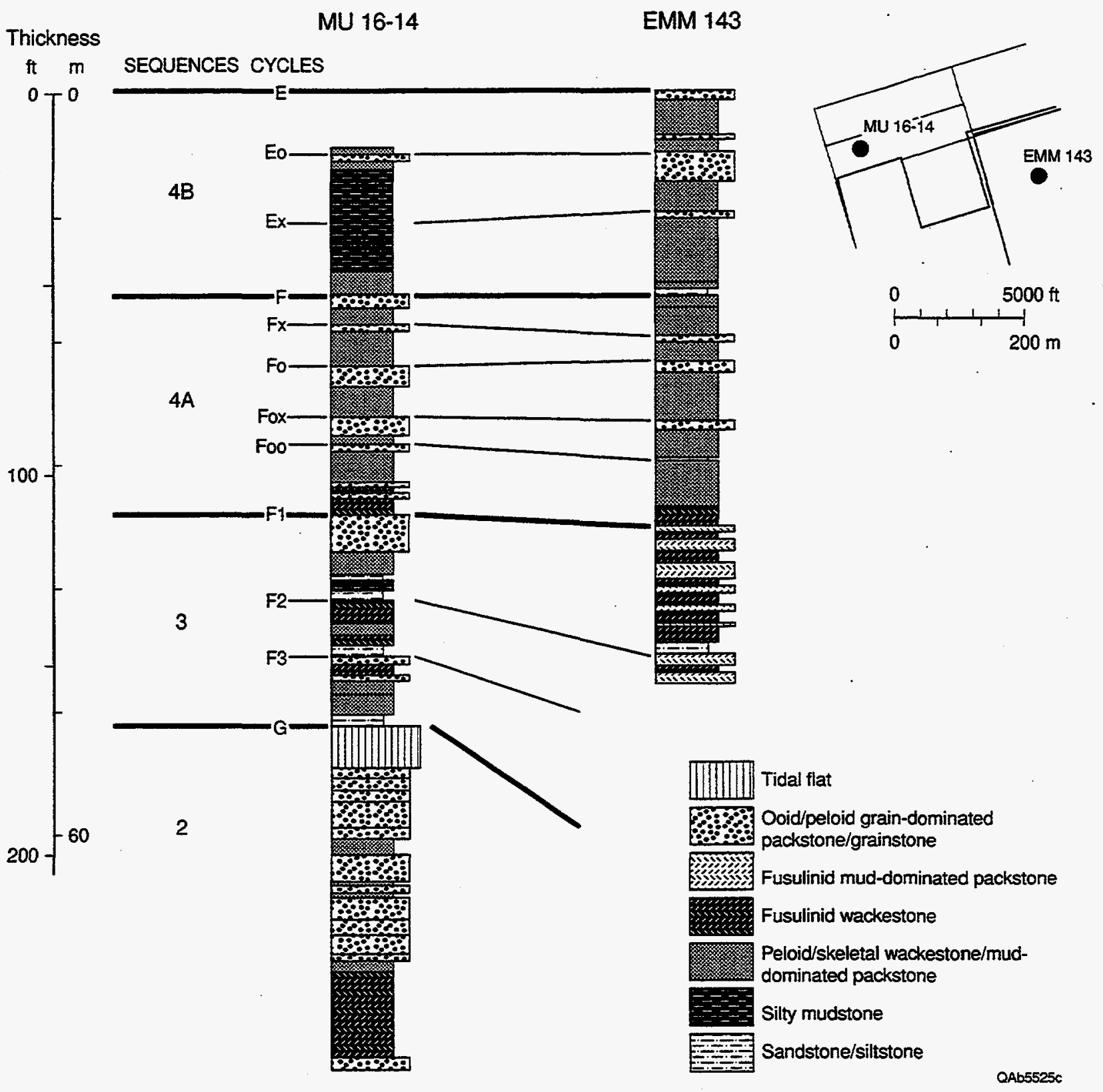

Figure 5. Core descriptions from wells Moss Unit 16-14 and Emmons Unit 143 showing sequences and high-frequency cycles.

cycles (F3-G, F2-F3) are outer ramp fusulinid dolowackestones marked by lower silty carbonates. The maximum flooding event is marked by the most landward (western) extent of fusulinids, which occurs in cycle F2-F3. The upper cycle (F1-F2) has a more typical shallowplatform vertical succession of silty carbonate to skeletal, peloid dolowackestone and is locally capped by a peloid grain-dominated dolopackstone. Fusulinid dolowackestones and grain- 
dominated dolopackstones are common basinward to the east. The basal silty dolomite layers make correlation of these cycles relatively easy (fig. 6).

HFS 4 is divided into eight HFC's (fig. 4), five in HFS 4A and three in 4B. The cycles in 4A are typical platform cycles consisting of basal skeletal/peloid mud-dominated dolostones with caps of peloid grain-dominated dolopackestone common in the west and less common in the east. The basal cycle, Foo-Fl, contains a thin basal interval of fusulinid wackestone that marks the flood back at the beginning of HFS 4. Log correlation of these cycles is not difficult (fig. 5) because the signature on gamma-ray logs is characterized by upward-cleaning cycles. However, this characteristic is less apparent in the eastern sector of the field. The base of HFS 4B is marked by an influx of quartz silt. Cycles in $4 \mathrm{~B}$ are more apt to contain capping grain-dominated dolostones and, occasionally, tidal-flat facies. Core and log correlation of the three upper cycles is difficult, suggesting short-range lateral facies changes consistent with the interpretation of a high-energy, shallow-water depositional environment (Ruppel and Bebout, 1996).

\section{ROCK FABRICS}

The petrophysical rock fabrics recognized in the South Cowden field from thin-section studies are illustrated in figure 7 and compared with the pore type classification of Lucia (1995). There are no limestone fabrics. The dolomite crystals range from well sorted to poorly sorted, a distinction that is not addressed in the Lucia classification. The distinction between petrophysical class 2 and class 3 is based on whether the crystal size that forms a supporting fabric is larger or smaller than 20 microns.

Fine, medium, and large crystalline dolograinstones of petrophysical class 1 are found within the upper interval of the G-H interval and the E-Eo interval (fig. 8). The intergrain pore space is commonly occluded by anhydrite, but anhydrite is often removed by dissolution on the eastern and southern flanks of the field. Dolomite crystal size typically ranges between 10 and 50 microns. However, the crystal size is greater than 100 microns in portions of the G-H interval in the South Cowden Unit. 


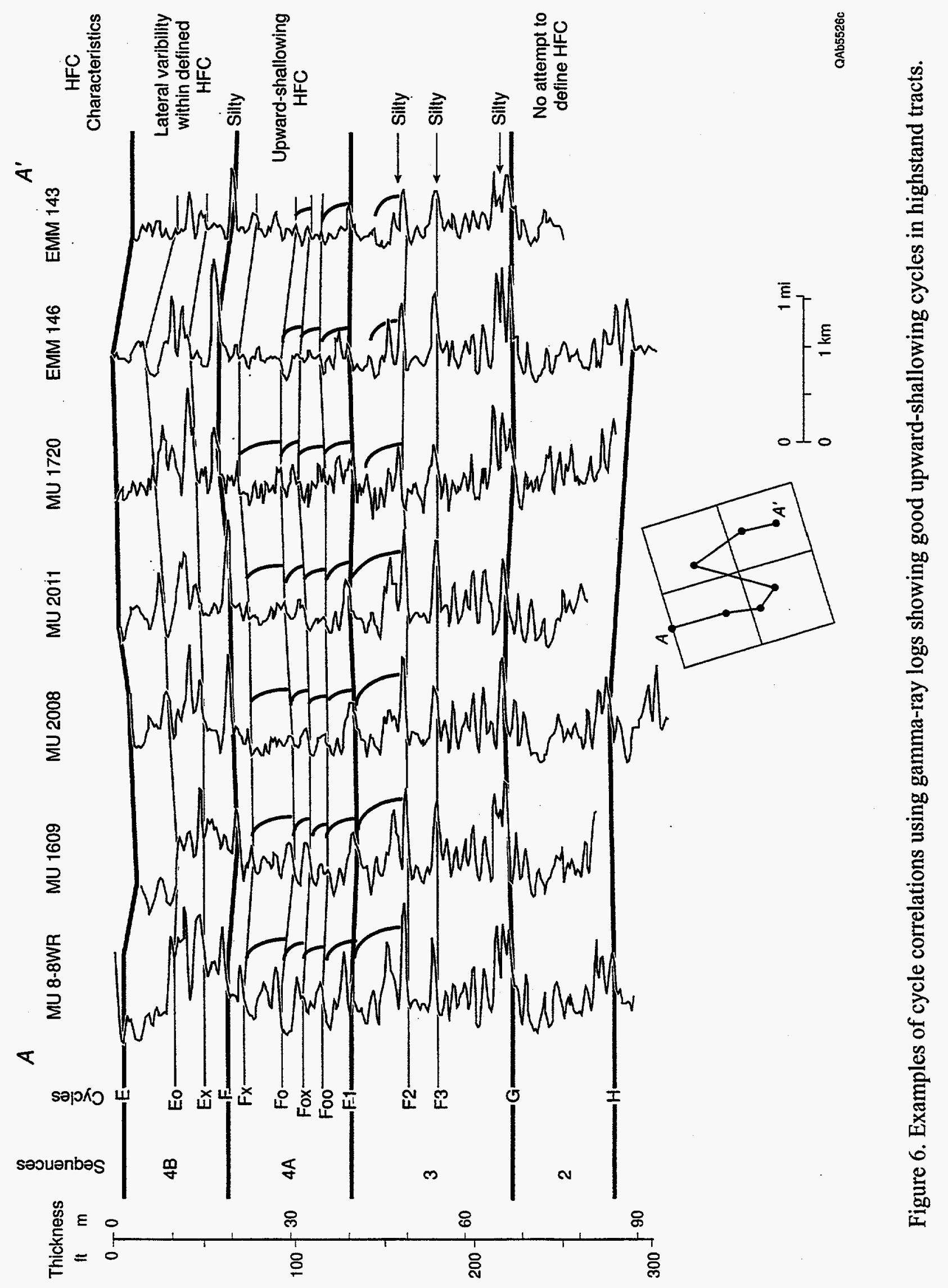




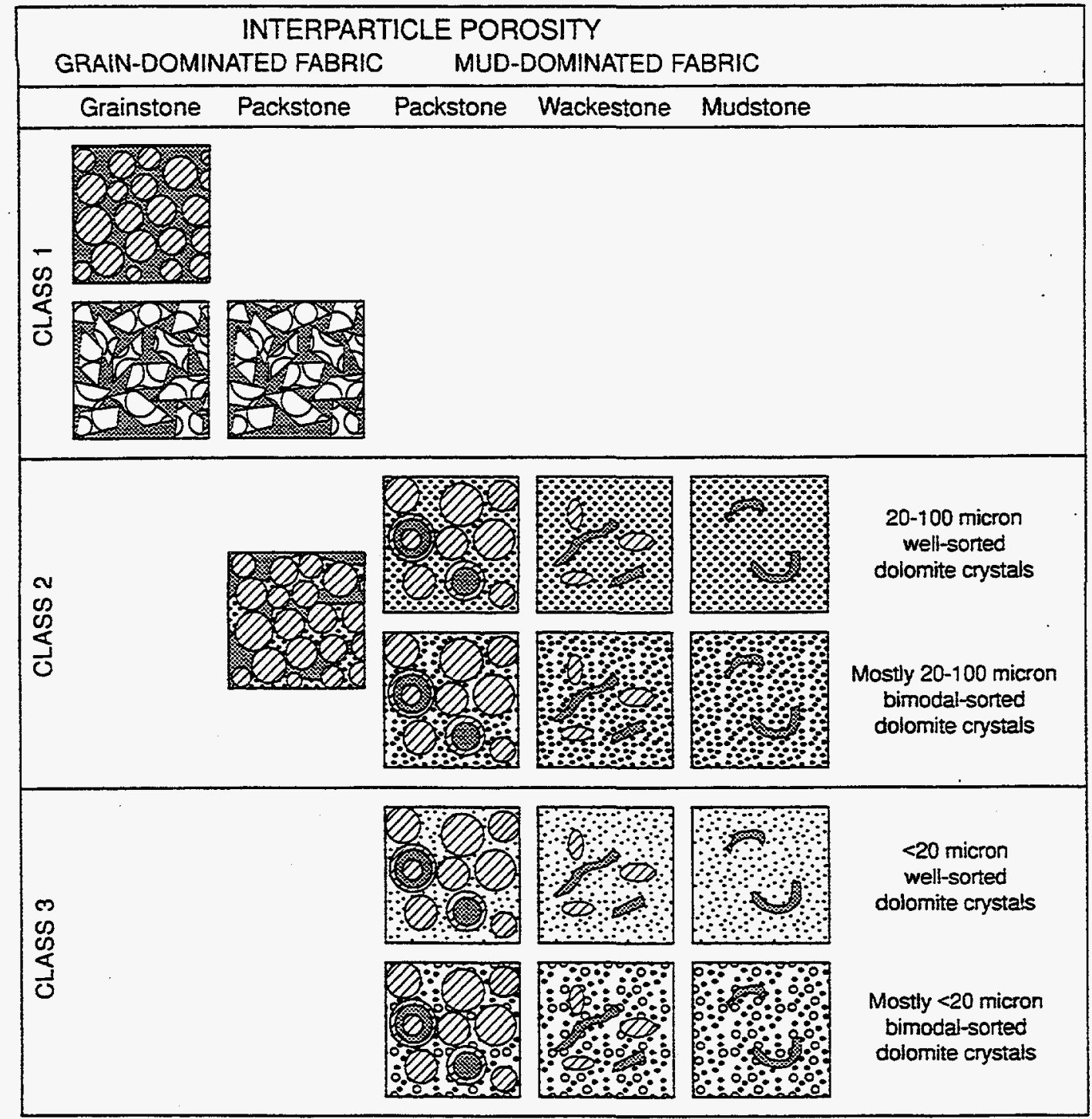

Note: bar is 100 microns

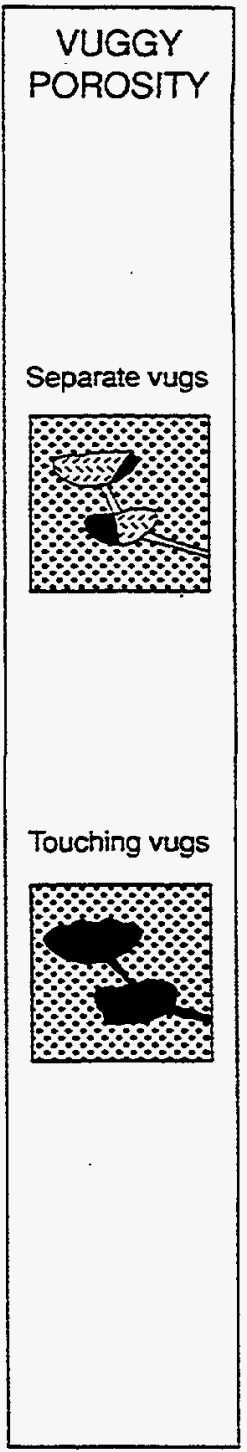

QAb5527e

Figure 7. Diagram illustration South Cowden rock-fabric/petrophysical classes.

Grain-dominated dolopackstones are found as thin beds capping high-frequency cycles (fig. 8). The class 2 fabrics are composed of 150 -micron peloid grains and dolomite crystals ranging from 10 to 30 microns. Grain-dominated fabrics composed of dolomite crystals greater than 100 microns, petrophysical class 1 , are found in portions of the G-H interval in the South Cowden Unit.

Dolowackestone is the most common texture in the reservoir. Within the study area, muddominated dolostones are typically composed of 20- to 50-micron dolomite crystals, 


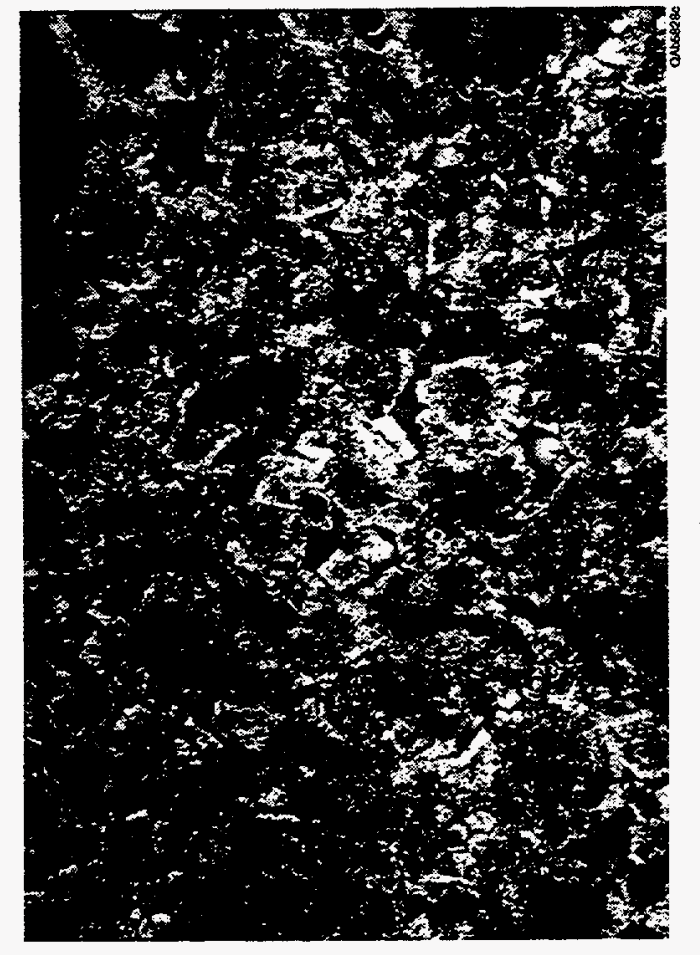

을

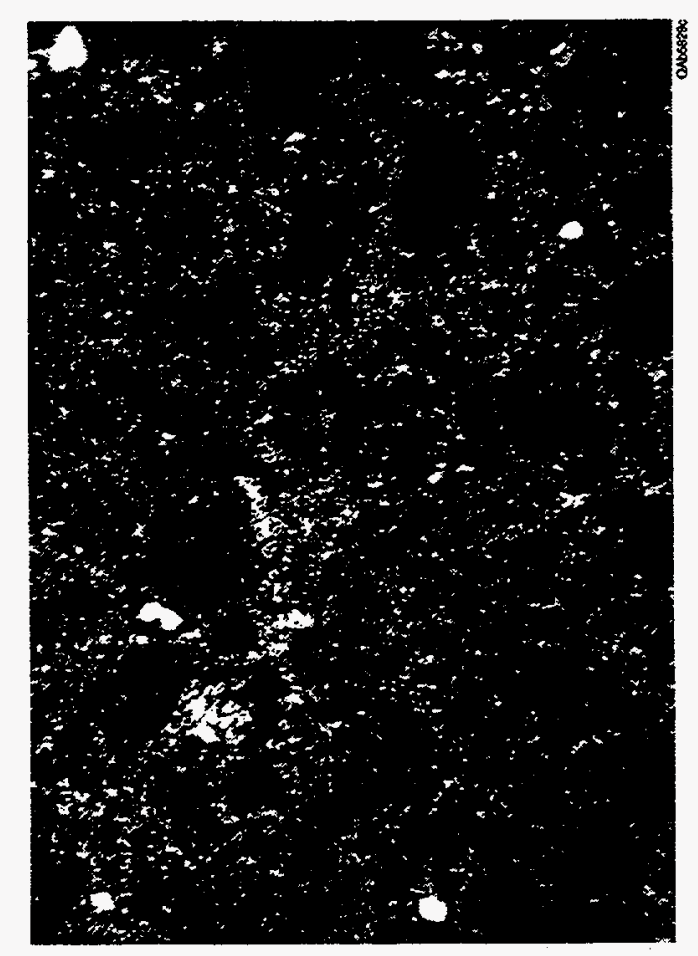

ॠ

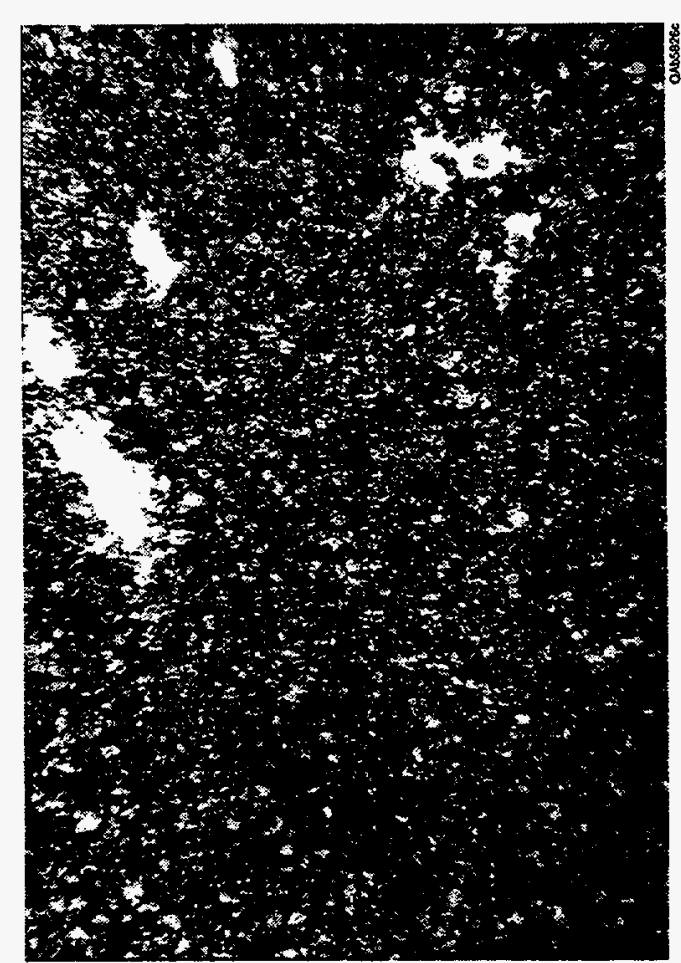

อ

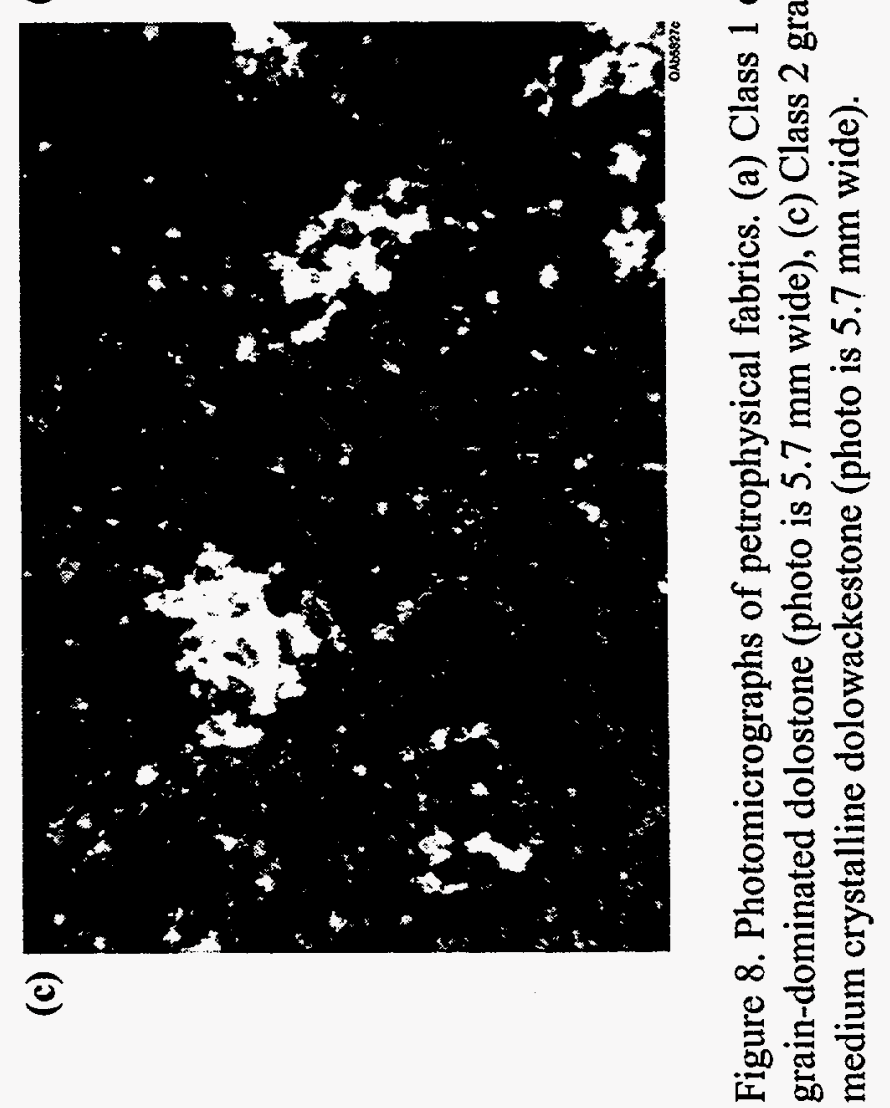


petrophysical class 2 (fig. 8). However, mud-dominated dolostones may be composed of dolomite crystals that range in size from 5 to 50 microns, presenting a poorly sorted crystal fabric. Where the larger-than-20-micron crystals form a supporting fabric, the rock is classified as petrophysical class 2 (fig. 9). Where the less-than-20-micron crystals form a supporting fabric, the rock is classified as class 3.

Vuggy porosity is present within the petrophysical class 2 fabrics as separate vugs (Svug) and touching vugs (Tvug). Occasional separate vugs in the form of fusulinid molds are found where anhydrite has been altered and dissolved. A touching-rug fabric composed of microfractures, fusumolds, and anhydrite-nodule molds is found on the southern and eastern flanks of the field where extensive anhydrite dissolution has occurred (fig. 10).

No geochemical studies to address the origin of the dolomite or, more importantly, the origin of the dolomite crystal size and sorting were included in the research. However, hypersaline reflux is generally agreed to be the dolomitization model for these rocks. The poorly sorted dolomite crystal fabric is mostly likely related to recrystallization of smaller crystals into larger crystals, perhaps resulting from the same waters that dissolved the anhydrite.

The absence of sulfate and the presence of anhydrite-nodule molds demonstrate dissolution of sulfate. The dissolution opens small fractures typically occluded by sulfate producing a touching-vug pore network. Evidence of anhydrite dissolution is not associated with any exposure event, indicating that it occurred well after deposition; it occurs within the oil column and in the residual oil zone, indicating that it occurred before the initial oil accumulation. Core and log data show that the dissolution is found on the eastern and southern flanks of the structure, suggesting that waters undersaturated with respect to anhydrite moved into the area from the east out of the Midland Basin, probably in response to compaction of the Midland Basin sediment. 
(a)

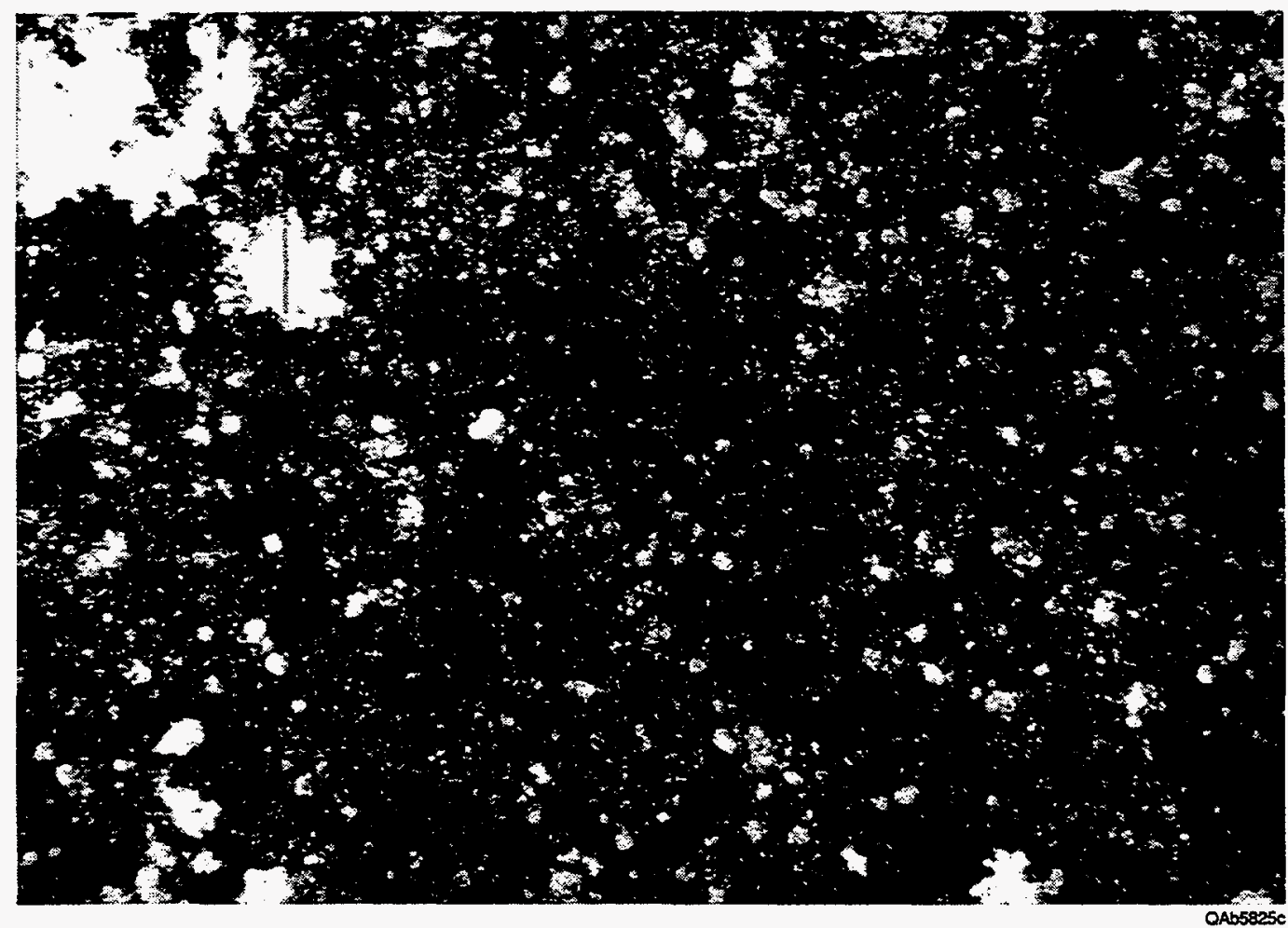

(b)

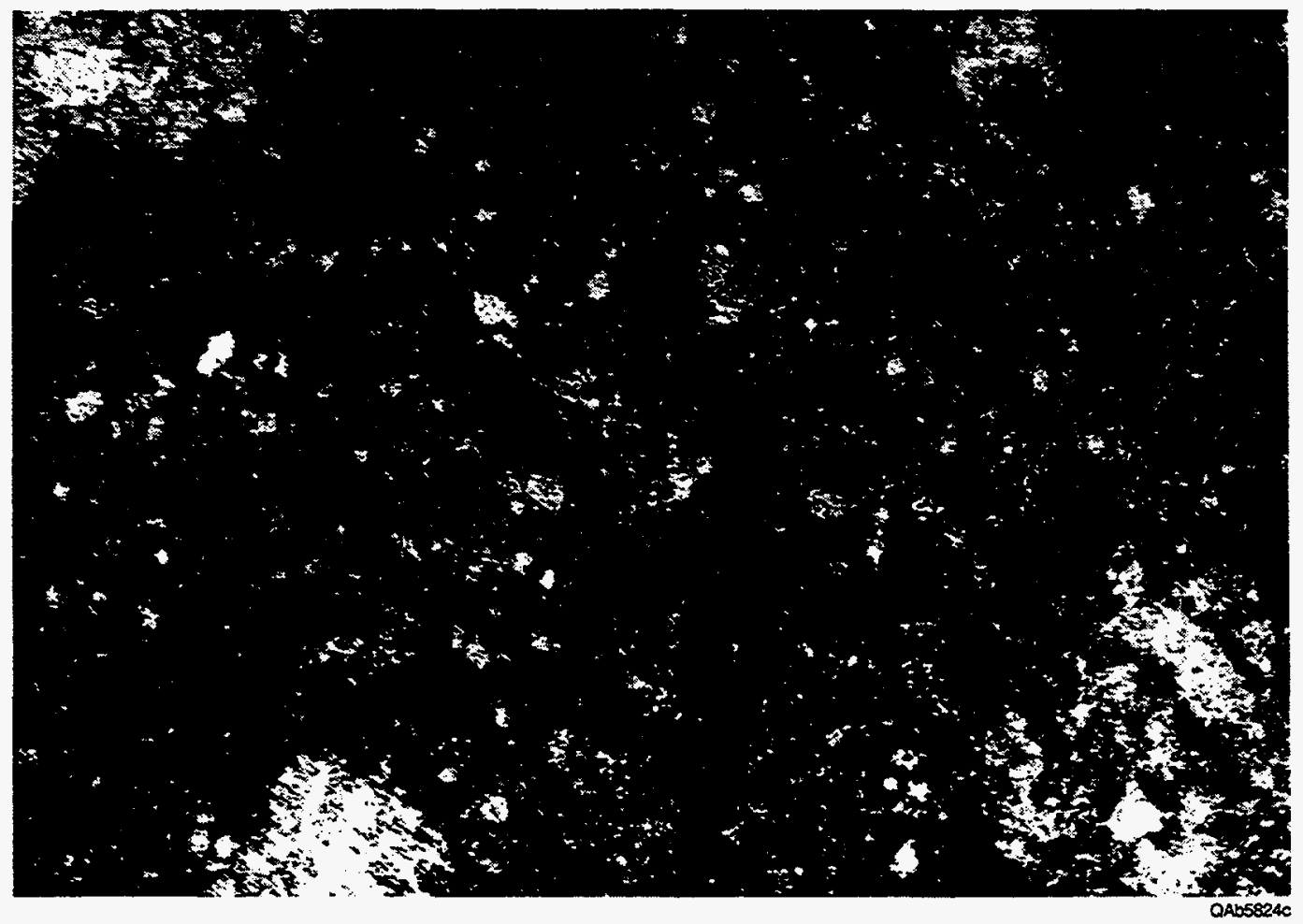

Figure 9. Photomicrographs of petrophysical fabrics (photos are $3.5 \mathrm{~mm}$ wide). (a) Class 2, poorly sorted dolomite crystals in a dolowackestone. The 20-100 micron crystals form the supporting fabric. (b) Class 3, poorly sorted dolomite crystals in a dolowackestone. The less-than-20-micron crystals form the supporting fabric. 
(a)

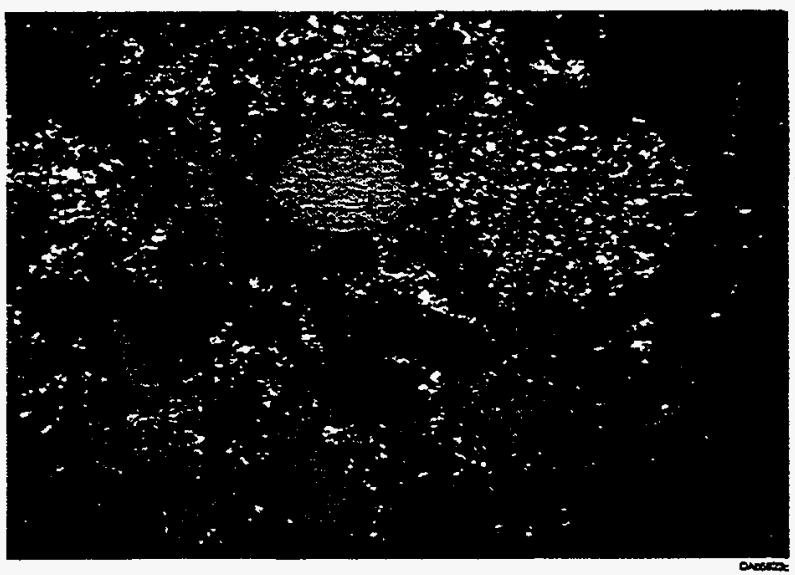

(c) (b)

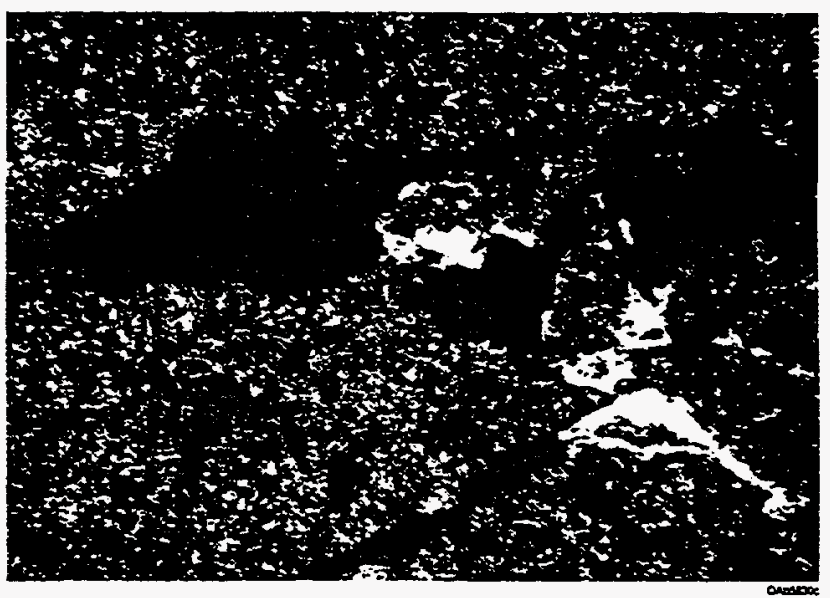

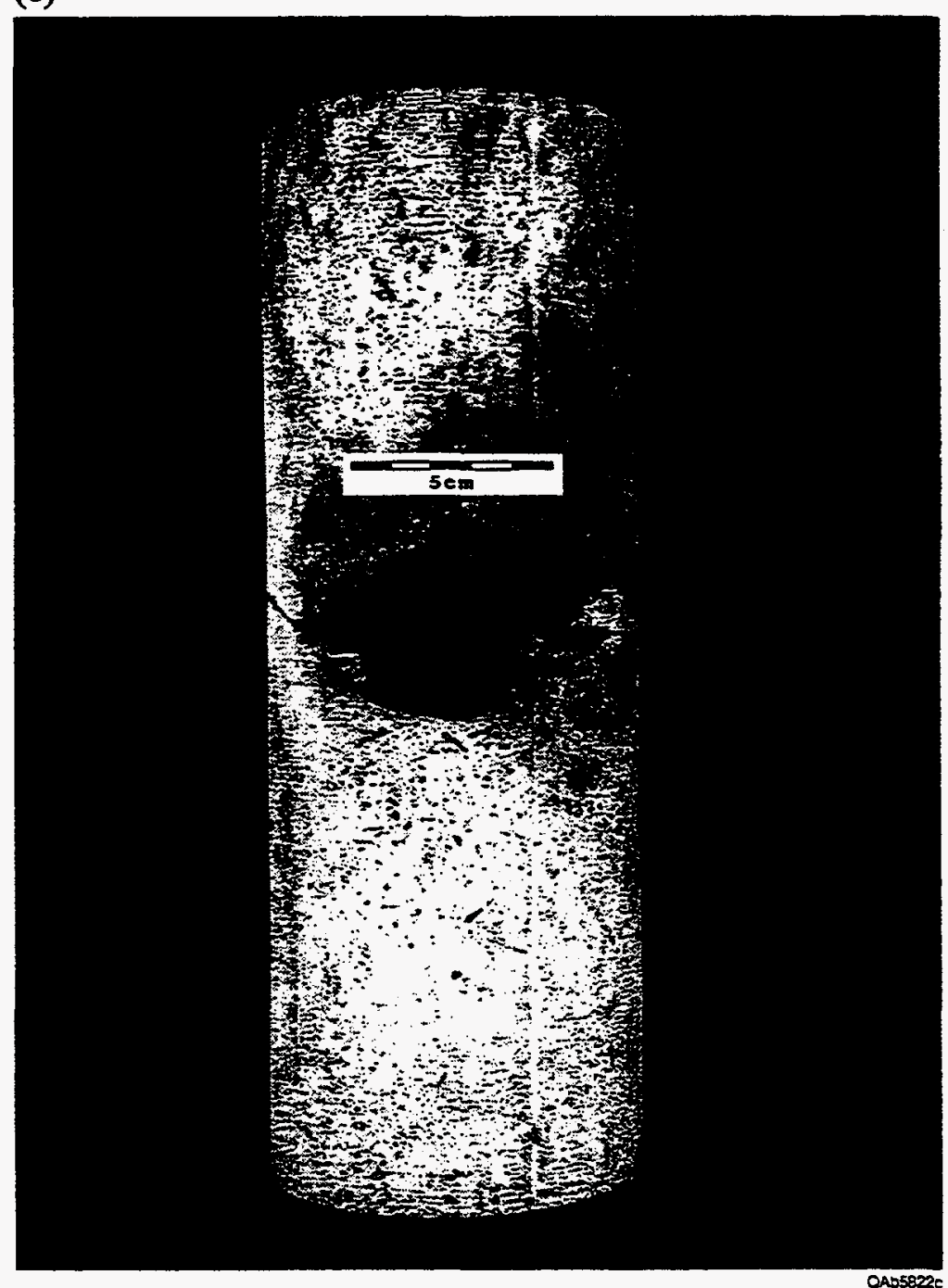

Figure 10. Photographs of petrophysical fabrics (photos are $5.7 \mathrm{~mm}$ wide). (a) Photomicrograph of fusumolds and microfractures occluded by anhydrite. (b) Photomicrographs of fusumolds connected by microfractures. (c) Core photo of a vug formed by dissolution of an anhydrite nodule. 


\section{PETROPHYSICS}

\section{Porosity Calculations}

The wide variety of wireline logs available for calculating porosity in uncored wells are listed in table 1. All log types, except SNP logs, have been calibrated with core data. Cased-hole and open-hole neutron logs show similar correlation coefficients with core data $(0.85$ and 0.89 respectively) (figs. 11 and 12). Cased-hole logs were run by a number of companies: Apollo, Schlumberger, Dresser Atlas, Welex, and McCullough. Dresser Atlas logs were discarded because their porosity values are significantly higher than porosity values from other companies (fig. 13). Neutron logs calibrated in counts per second were not used in this study because of their inherent inaccuracy. No attempts to calibrate the Dresser Atlas or the neutron logs with counts per second were made.

Table 1. Wireline logs available in South Cowden field study area.

No. of wells

10

33

16

58

$\frac{40}{204}$
Log type

Neutron logs calibrated in counts per second Open-hole neutron logs calibrated in porosity Cased-hole neutron logs calibrated in porosity Sidewall neutron logs Acoustic logs Neutron/density logs with occasional acoustic logs Total wells

The 43 neutron logs calibrated in porosity units ( 10 open-hole and 33 cased-hole) were normalized using overlying anhydrite beds as zero porosity. Because there are no cores available from these 43 wells, porosity transforms were developed using core data and neutron logs from wells with more complete log suites. Open-hole neutron logs were calibrated with core data in seven wells (fig. 11) and cased-hole logs in three wells (fig. 12). The transforms developed are presented below. 


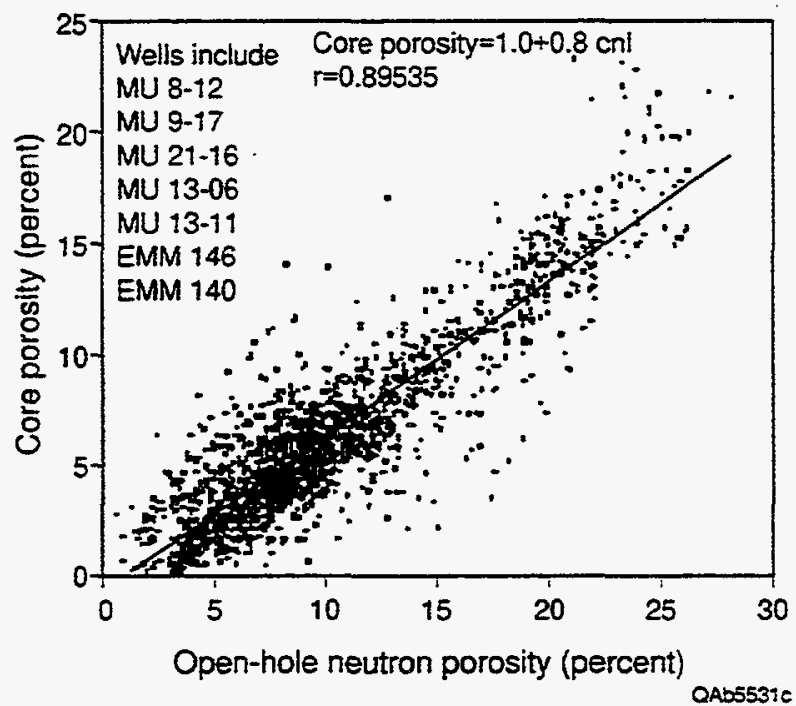

Figure 11. Cross plot of core porosity and open-hole neutron log porosity values for seven wells.

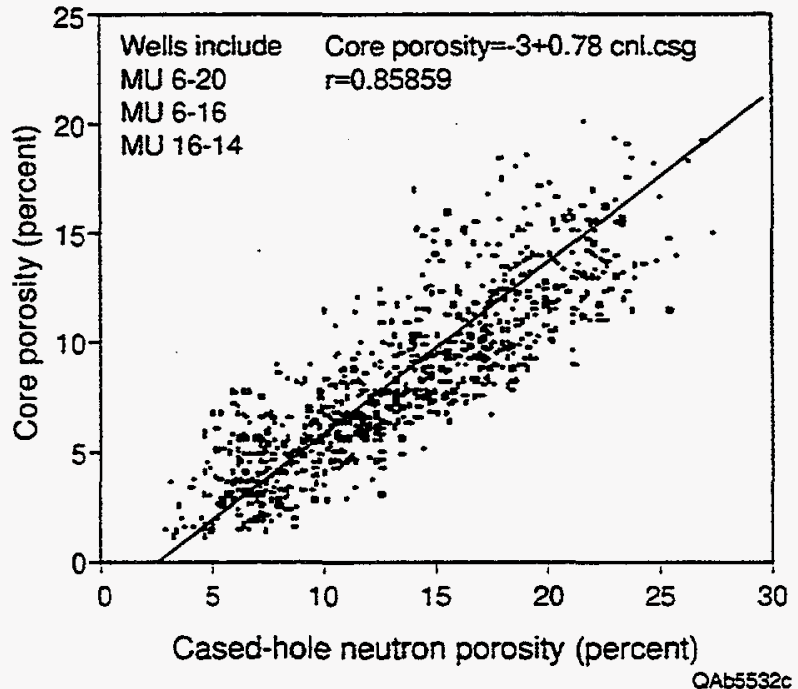

Figure 12. Cross plot of core porosity and cased-hole neutron porosity values for three wells. 


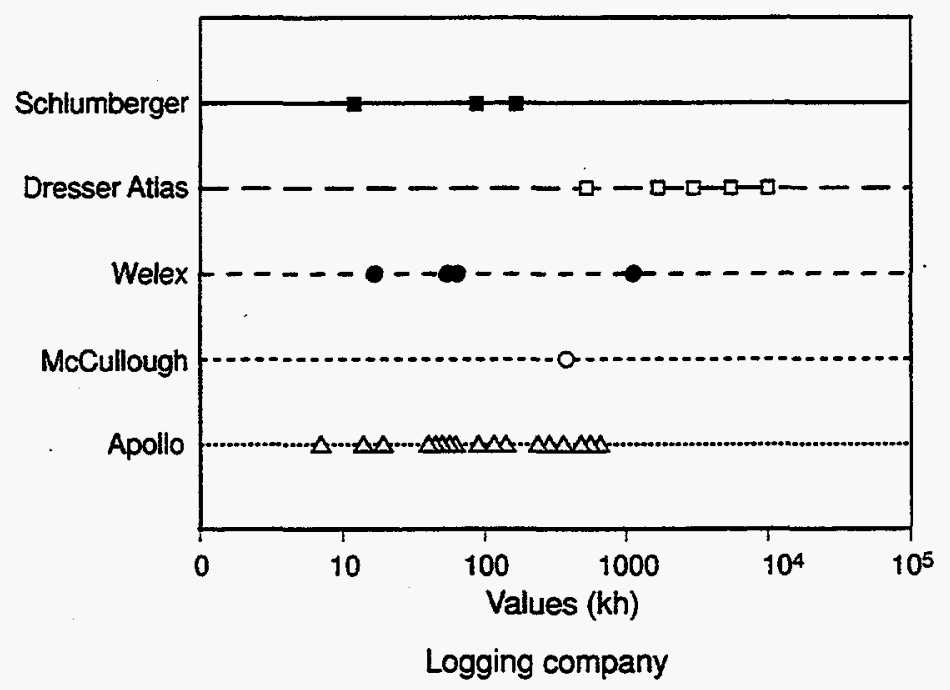

OAb5533C

Figure 13. Comparison of average porosity values in the reservoir interval from the five cased-hole logging companies. Dresser Atlas values are much higher than values from other companies and were not used in this study.

Open-hole neutron porosity transform:

$$
\emptyset=-1.0+0.8 \mathrm{CNL} \text {. }
$$

Cased-hole neutron porosity transform:

$$
\emptyset=-3.0+0.78 C N L \operatorname{csg} .
$$

Gypsum has a large effect on neutron and density logs because the bound $\mathrm{H}_{2} \mathrm{O}$ in the mineral is counted as pore space by the neutron $\log$, and the low density of 2.3 leads to overstated porosity on the density log. However, gypsum has about the same effect as anhydrite on the acoustic log. As will be discussed later, there is a large difference between neutron/density porosity and acoustic porosity values in a number of wells. 
The difference between neutron/density porosity and acoustic porosity values could be accounted for by the presence of gypsum. Gypsum has been observed in many thin sections, but rarely in amounts over 10 percent and only in scattered samples. Fifty-one samples were taken from interval 4594-4646 in well Emmons 210, where the acoustic porosity is much less than the neutron/density porosity, and the samples were analyzed for gypsum by X-ray diffraction (XRD) analysis. Minor amounts of gypsum were found in only four of the samples. Therefore, insufficient gypsum is present to account for the difference between acoustic and neutron/density porosity values. As will be shown later, the difference is due to the presence of a touching-vug pore geometry.

Developing a porosity transform for acoustic logs presented a serious problem because of the poor correlation between porosity and transit time. Acoustic logs were calibrated with both core porosities and porosity from neutron-density cross plots. Acoustic logs can be divided into three groups based on neutron-density porosity/transit-time cross plots (fig. 14). Group 1 is characterized by the Wyllie time-average curve with a fluid velocity of $180 \mu \mathrm{s} / \mathrm{ft}$. This group is characterized by interparticle pore space. Group 2 is characterized by a pseudo-fluid velocity of $145 \mu \mathrm{s} / \mathrm{ft}$. This group has minor amounts of separate-vug porosity as well as interparticle pores. Group 3 is characterized by a pseudo-fluid velocity of $133 \mu \mathrm{s} / \mathrm{ft}$. This group is characterized by the presence of touching vugs. These groups are spatially distributed (fig. 15) and, as discussed in a later section, can be correlated with the dissolution and alteration of anhydrite.

There are 56 acoustic logs in acoustic group 1 that have been calibrated to porosity using core data from 6 wells. The porosity transform used for acoustic logs in the acoustic group 1 area is

$$
\emptyset_{\mathrm{f}}=-0.37+0.008 \Delta t \text {. }
$$

Three wells in the acoustic group 2 have only acoustic logs. The porosity transform for this group is

$$
\emptyset_{f}=-0.48+0.010 \Delta t \text {. }
$$




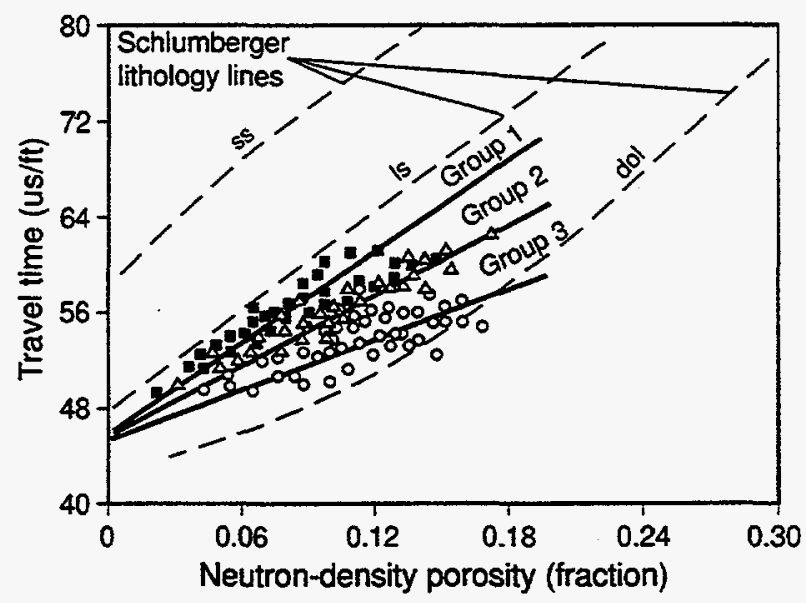

- Group 1; Unaltered anhydrite, interparticle porosity

Group 2; Altered anhydrite, interparticle and separate-

$\triangle$ vug porosity

- Group 3; Dissolved anhydrite, interparticle, separate- and

touching-vug porosity

QAb5534C

Figure 14. Cross plot of neutron-density porosity and acoustic traveltime showing distinct porosity transforms for each of three rock fabrics.

Twelve wells with only acoustic logs fall in the area of acoustic group 3 . The porosity transform for this area is given below:

$\emptyset_{\mathrm{f}}=-0.53+0.012 \Delta \mathrm{t}$

\section{Capillary Properties}

\section{Moss Unit Data}

Mercury capillary-pressure measurements and thin sections for 61 samples were contributed to the study by Unocal. Thin sections were described in terms of dolomite crystal size, size and sorting on the basis of relic depositional texture, interparticle porosity, and separate-vug porosity. The samples were then grouped into the three interparticle rock-fabric/petrophysical classes established by Lucia (1995). The volume of separate-vug porosity in the data set was small (less than 3 percent). 


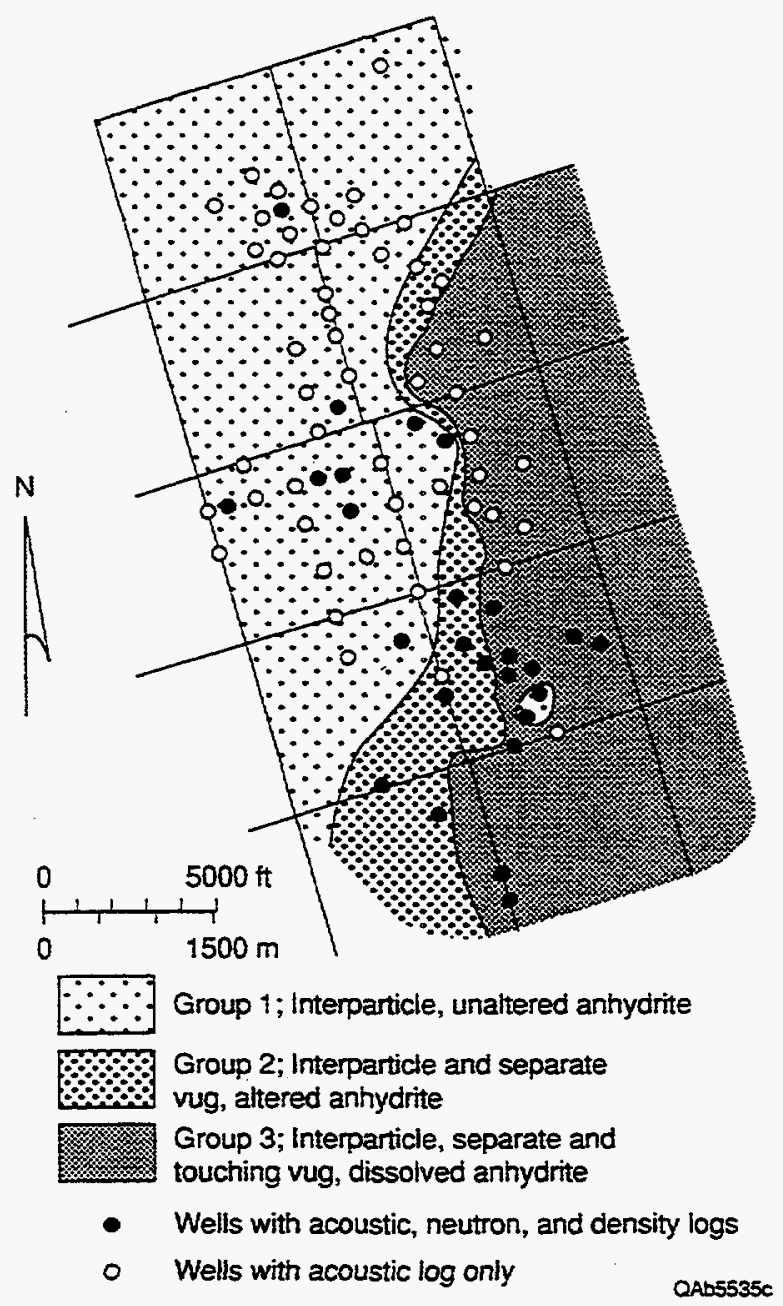

Figure 15. Map showing distribution of rock fabrics based on acoustic porosity cross plots (fig. 14). The acoustic groups also identify the diagenetic facies.

Capillary pressure was converted to reservoir height using the reservoir data given in table 2 .

Table 2. Parameter used in converting capillary-pressure data into reservoir height.

\section{Oil/water Mercury/air}

$\begin{array}{lc}\text { Tau }(\tau) & 30.2 \\ \text { Theta }(\theta) & 45^{\circ} \\ \text { Oil density }\left(\rho_{\mathrm{o}}\right) & 0.803 \\ \text { Water density }\left(\rho_{\mathrm{w}}\right) & 1.1\end{array}$


Class 1 samples are three dolograinstones (fig. 16). There are too few data to develop a relationship between capillary pressure, porosity, and saturation. However, the capillary-pressure curves are similar to the class 1 curves presented by Lucia (1995). Therefore, the generic class 1 equation developed by Lucia (1995) is used in all calculations in this study:

Lucia (1995) class 1: $\mathrm{S}_{\mathrm{W}}=0.022 \times \mathrm{H}^{-0.316} \times \phi^{-1.745}$.

Class 2 includes 35 samples ranging from grain-dominated dolopackstones to medium crystalline mud-dominated dolopackstones and wackestones. Ten mud-dominated fabrics are composed of poorly sorted dolomite crystal sizes (medium to fine size), but the 20-100 size dominates the pore size (table 3 ).

Table 3. Class 2 sample descriptions.

Fabric description

Grain-dominated dolopackstones

Fine crystalline

Medium crystalline

Total

Mud-dominated dolopackstones/wackestones

Medium crystalline

Medium/fine crystalline

Total
No.

12

$\frac{8}{20}$

5
10
15

The 35 capillary-pressure curves were averaged into three porosity groups listed in table 4 .

Table 4. Average porosity for Class 2 porosity groups.

$\begin{array}{ccc}\text { Porosity range } & \text { Avg. porosity } & \text { No. of sps. } \\ \text { 5-10 } & 7.66 & 10 \\ 10-15 & 12.39 & 15 \\ 15-20 & 17.36 & 10\end{array}$

The average capillary-pressure curves for the three groups are illustrated in figure 17. A saturation model based on these curves is presented below and compared with the average capillary-pressure curves in figure 17. The model is similar to that presented by Lucia (1995):

South Cowden class 2: $\mathrm{S}_{\mathrm{w}}=0.727 \times \mathrm{H}^{-0.549} \times \phi^{-1}$;

Lucia (1995) class 2: $\quad \mathrm{S}_{\mathrm{w}}=0.1440 \times \mathrm{H}^{-0.407} \times \phi^{-1.440}$. 


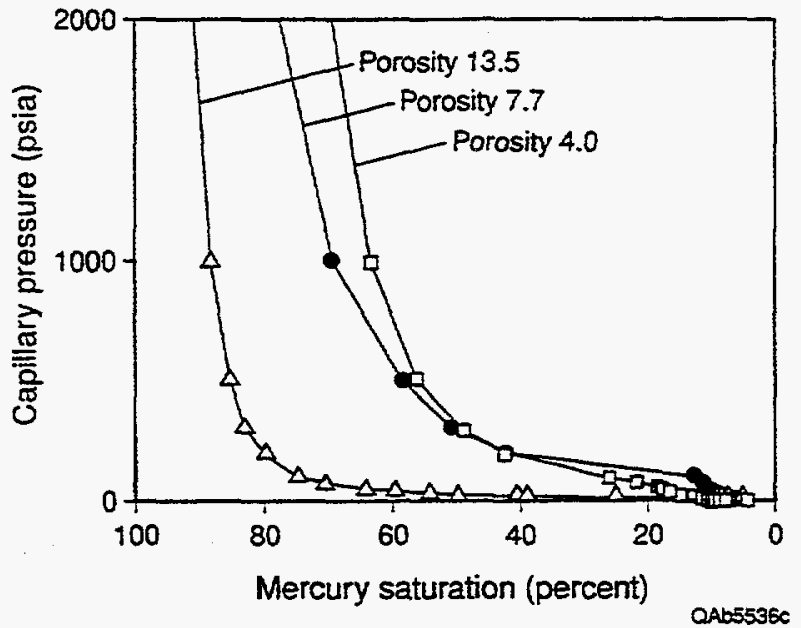

Figure 16. Capillary pressure graphs for three grainstones of varying porosity from the Moss Unit.

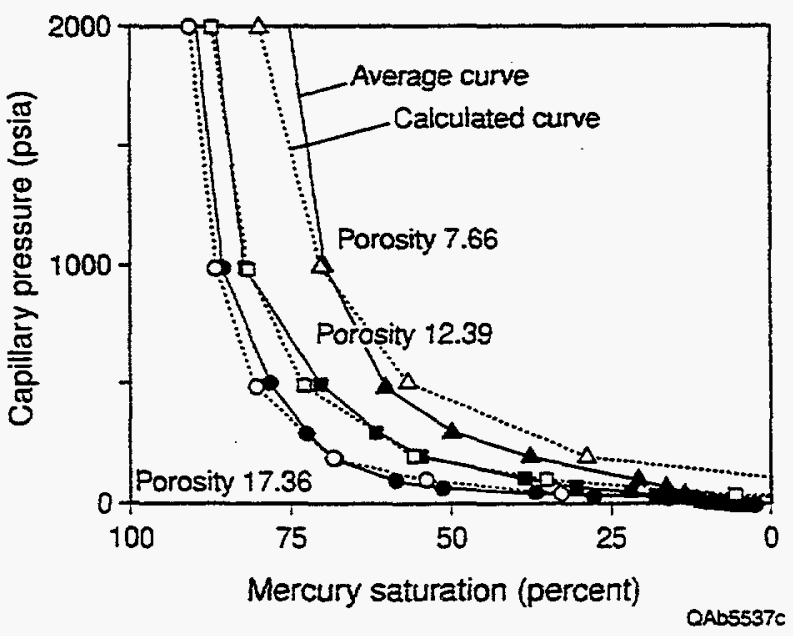

Figure 17. Petrophysical class 2 average capillary-pressure curves for three porosity groups compared with curves calculated from the class 2 saturation model using identical porosity values. Moss Unit data. 
Class 3 includes 23 samples. All samples have a wackestone texture, but the dolomite crystals range from fine to a mixture of fine, medium, and large. However, the fine crystal size dominates the pore size in all these samples (table 5).

Table 5. Class 3 sample descriptions.

Fabric Description $\quad$ No.

Dolowackestone

Fine crystalline

Fine/medium crystalline

Fine/large crystalline

Total

$\frac{1}{23}$

The 23 capillary-pressure curves in this class are averaged into three porosity groups as listed in Table 6.

Table 6. Average porosity for Class 3 porosity groups.

$\begin{array}{ccc}\text { Porosity range } & \text { Avg. porosity } & \text { No. of sps. } \\ 4-8 & 6.43 & 8 \\ 8-12 & 9.97 & 12 \\ 12-17 & 14.93 & 3\end{array}$

The average capillary-pressure curves for the three groups are illustrated in figure 18. A saturation model based on these curves is presented below and compared with the average capillary-pressure curves in figure 18. The model is similar to that presented by Lucia (1995):

South Cowden class 3: $\mathrm{S}_{\mathrm{w}}=0.8505 \times \mathrm{H}^{-0.5306} \times \phi^{-1.0234}$;

Lucia (1995) class 3: $\quad \mathrm{S}_{\mathrm{w}}=0.6110 \times \mathrm{H}^{-0.505} \times \phi^{-1.210}$.

The change in saturation characteristics with a change in rock fabric can be illustrated by plotting capillary-pressure curves from samples with different fabrics but similar porosity values (fig. 19). At any given capillary pressure (reservoir height), water saturation increases with petrophysical class number, assuming a constant porosity value. 


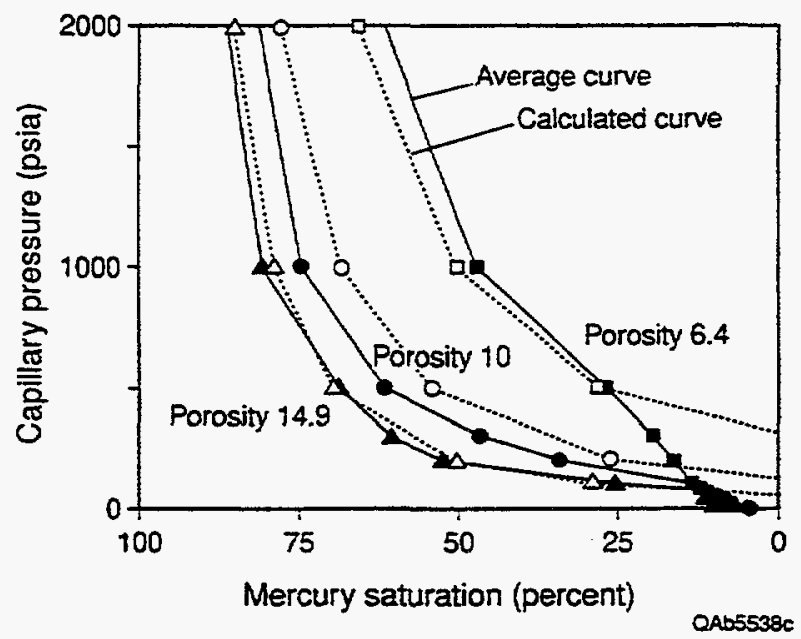

Figure 18. Petrophysical class 3 average capillary-pressure curves from three porosity groups compared with curves calculated from the saturation model using identical porosity values. Moss Unit data.

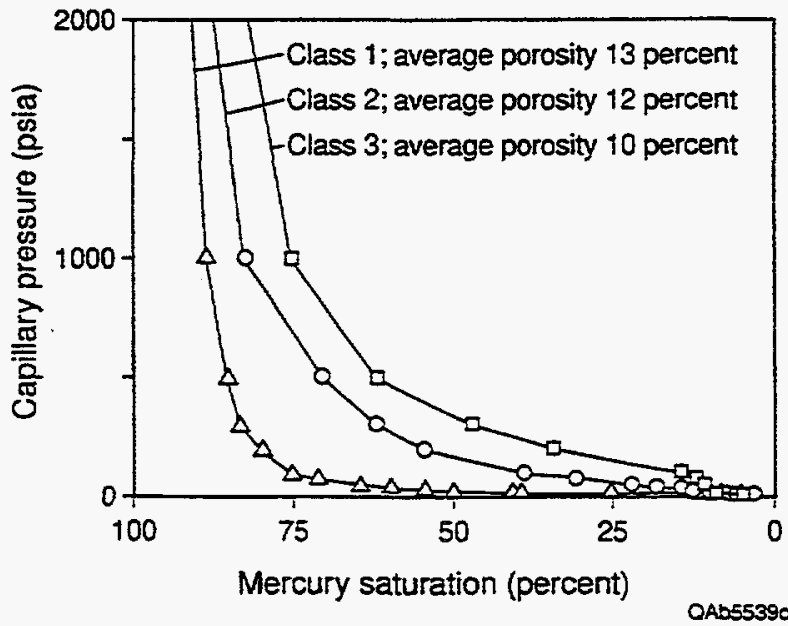

Figure 19. Comparison of capillary properties from the three petrophysical classes at similar porosity values. 


\section{Emmons Unit Data}

Mercury capillary-pressure measurements and thin sections for eight samples from the Emmons Unit were available for study. Two samples are medium crystalline dolowackestones from the area of touching-vug porosity (Emmons 142). The capillary-pressure characteristics (fig. 20) are not markedly different from the characteristics of the Moss Unit samples, where touching-vug porosity is not present because capillary-pressure measurements do not provide a good description of separate-vug or microfracture porosity.

Two dolograinstones and four medium crystalline grain-dominated dolopackstones are from an area of altered anhydrite 2 , which contains separate-vug porosity. The capillary-pressure characteristics (fig. 21) of these samples are also not markedly different from the characteristics of the Moss Unit samples.

\section{Water Saturation Calculations}

\section{Original Water Saturation}

Calculation of the original water saturation was accomplished by using relationships between water saturation, rock fabric, porosity, and reservoir height developed from capillarypressure curves. This approach was taken because many of the wells were drilled after the waterflood was initiated and some intervals are flooded. Rock fabric studies indicate that the reservoir rock within the study area can be characterized as petrophysical class 2 , although class 3 fabrics are known to be locally present. Therefore, the class 2 relationship between porosity, saturation, and reservoir height given below was used to estimate the original water saturation.

Several infill wells with modern logs and core encountered unswept areas of the field and, in these wells, Archie water saturations can be used to develop a transform between porosity and water saturation. One of these wells is the Moss Unit 8-12. Core descriptions show the rock 


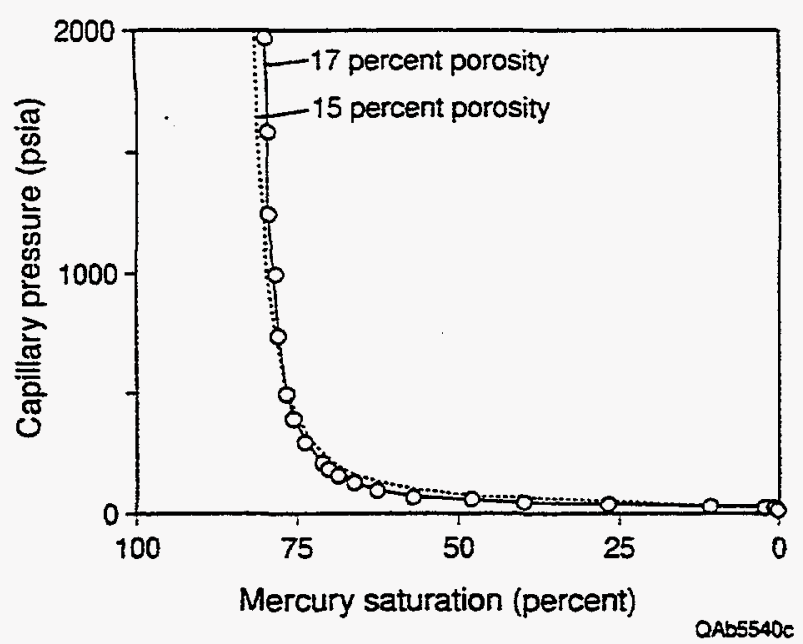

(a)

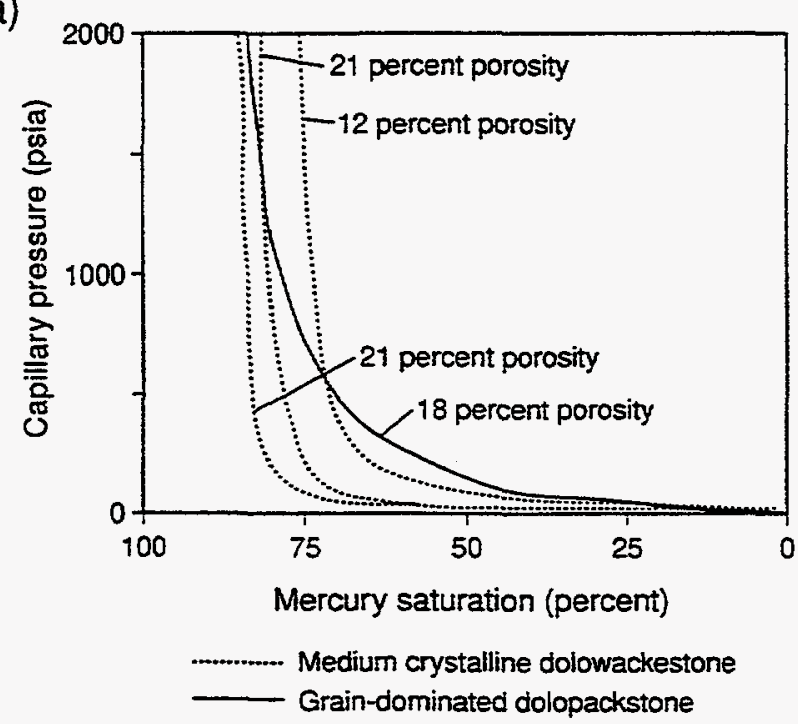

(b)

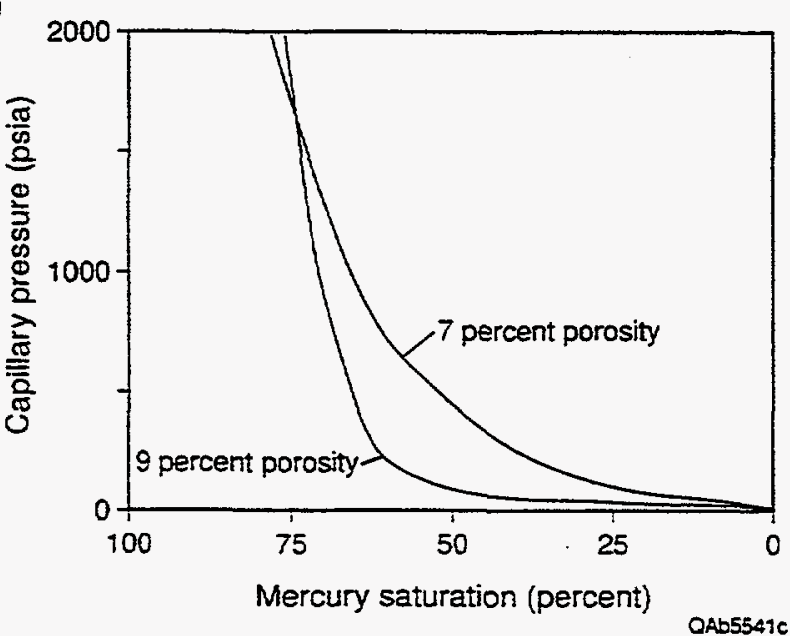

Figure 20. Capillary-pressure curves from class 2, touching-vug fabric, acoustic group 3, Emmons Unit 142.
Figure 21. Capillary-pressure curves from altered sulfate fabric, acoustic group 2, Emmons Unit 143. (a) Medium crystalline dolowackestone and grain-dominated dolopackestone, and (b) dolograinstone. 
fabrics to be petrophysical class 2 . The saturation transform developed from this well is given below (fig. 22). The Moss Unit 8-12 is well above the transition zone, and this transform can be used only above the transition zone:

$\mathrm{S}_{\mathrm{w}}=0.026 \times \phi^{-1.04}$

The class 2 capillary-pressure model was tested by comparing it to the Archie saturation transform from Moss Unit 8-12. The two models are in agreement if a reservoir height of $350 \mathrm{ft}$ is inserted into the capillary-pressure model (fig. 23) and the height is compatible with the depth of the reservoir interval in Moss Unit 8-12.

\section{Transition Zone Considerations}

The transition zone can be defined by capillary-pressure curves if the zero capillarypressure level is defined. Historical records place the original oil-water contact (OOWC), assumed to approximate 50 percent water saturation, at a subsea depth of -1850 . However, in the western sector of the field, an OOWC at subsea -1750 has been suggested from production tests. This difference may be the result of rock fabric or porosity changes across the field. Another possible explanation is suggested by the fact that, on the eastern edge of the field, there is a $100-\mathrm{ft}$ residual oil zone.

Core analyses from wells Moss Unit 6-20, Emmons 121, and South Cowden 8-19 on the eastern and southern flank of the field show residual oil between -1850 and -1950 with an average oil saturation of 20 percent. This interval produces water, and the oil saturation is interpreted to be residual oil left behind after a second migration event. On the west side of the field, core data from Moss Unit 1306 shows no oil saturation below -1832 , suggesting that there is no residual oil zone on the west side.

The second migration event was most likely caused by Basin and Range deformation during the Tertiary (Miocene?) and that caused strata to tilt to the east. This tilting would cause the oilwater contact to rise, placing the reservoir in capillary imbibition rather than drainage. The 


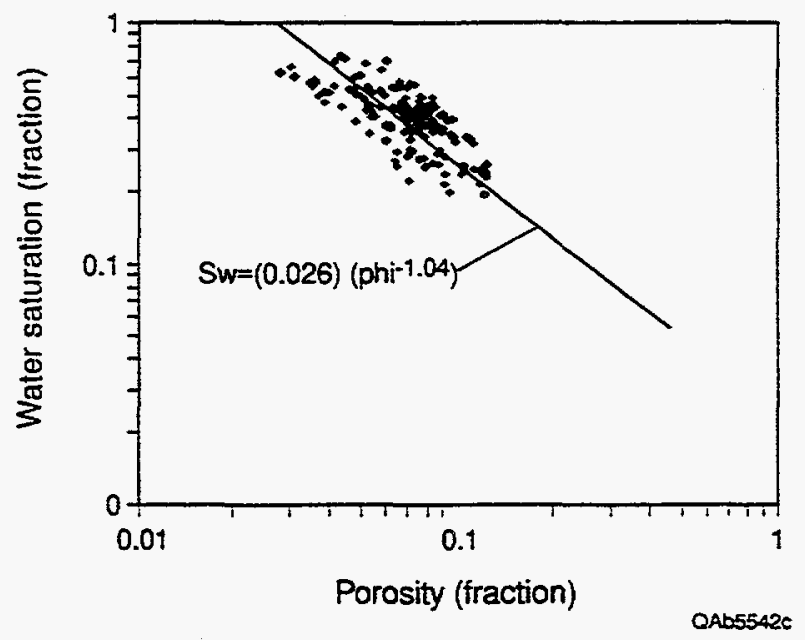

Figure 22. Cross plot of porosity and log calculated water saturation from Moss Unit 8-12 showing water saturation-porosity transform used to calculate original water saturation above the transition zone.

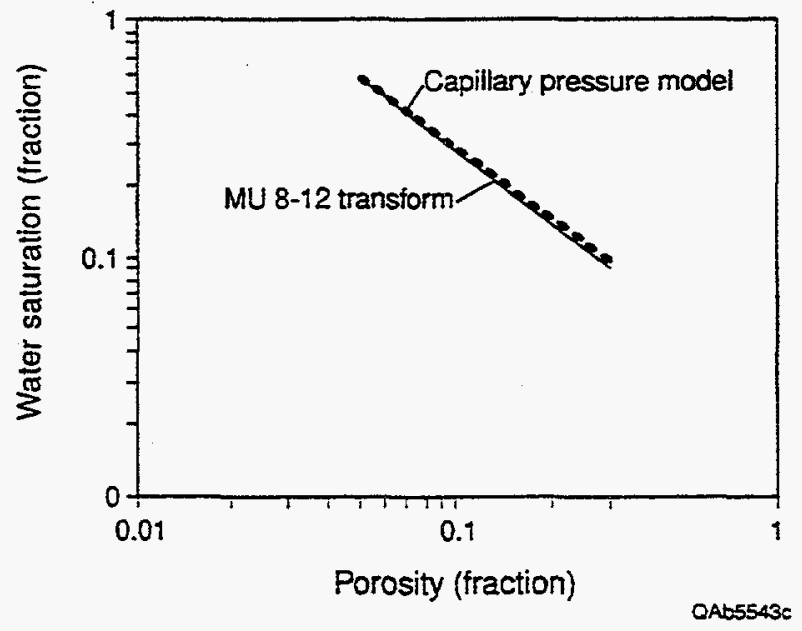

Figure 23. Comparison of capillary-pressure saturation model using a reservoir height of $350 \mathrm{ft}$ with the saturation transform from Moss Unit 8-12 (see fig. 22). 
drainage phase occurs when the capillary pressure increases (fig. 24). This occurs during the initial migration phase because the accumulation of oil increases the reservoir height and thus the capillary pressure (fig. 25a). The imbibition phase occurs when the capillary pressure decreases (fig. 24). This occurs during the remigration of oil during structural tilting because the reduced reservoir height decreases the capillary pressure (fig. 25b). The wetting phase (water) is pulled into larger pores by surface attraction, whereas oil is expelled. Imbibition capillary-pressure curves predict lower water-saturation values than drainage curves, an effect that should be accounted for when predicting water saturation in the transition zone.

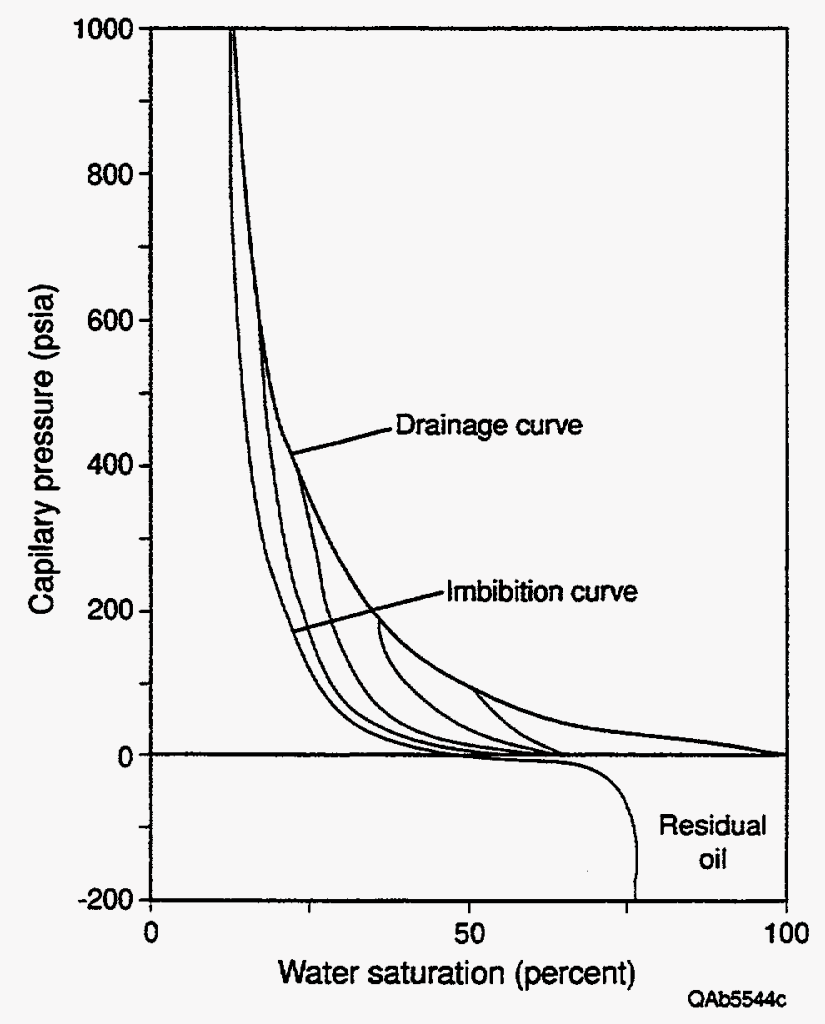

Figure 24. Diagrammatic illustration of capillary-pressure curves for petrophysical class 2 with 10 percent porosity illustrating the difference in saturation values between drainage and imbibition curves. 
(a) Reservoir

$$
\text { ft } \mathrm{m}
$$

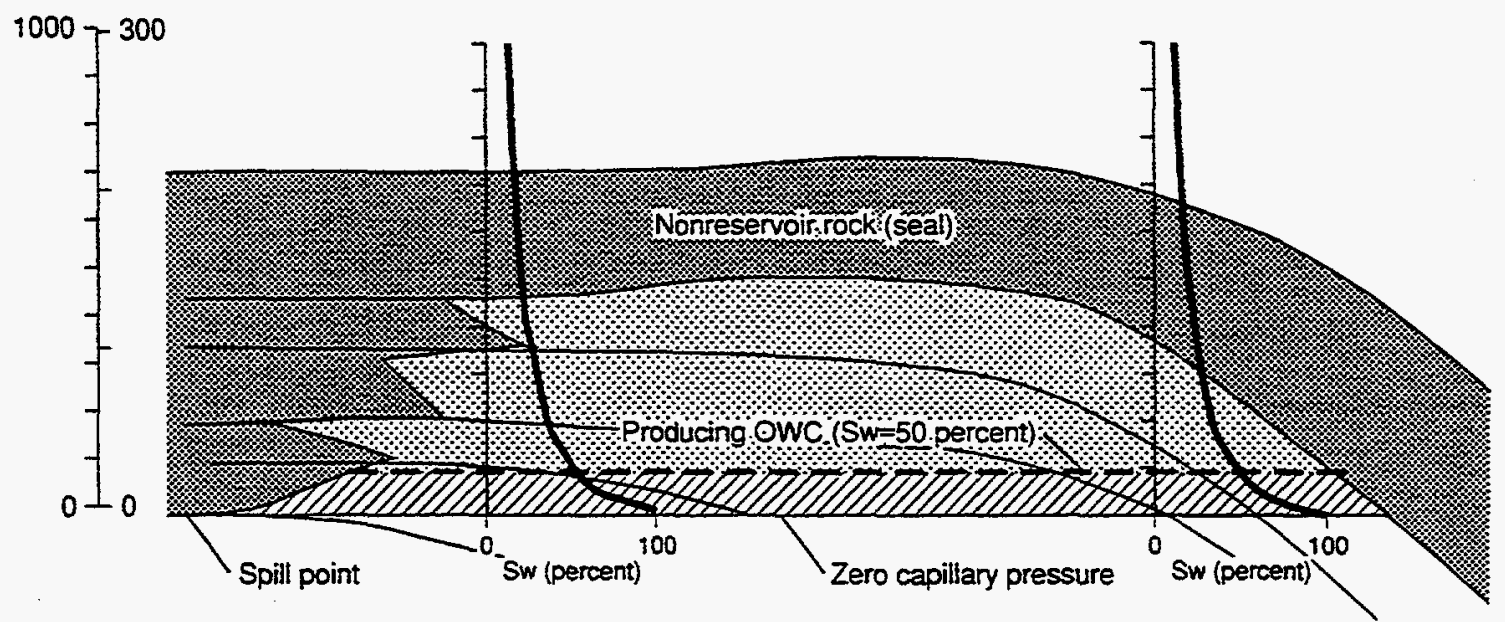

(b) Reservoir
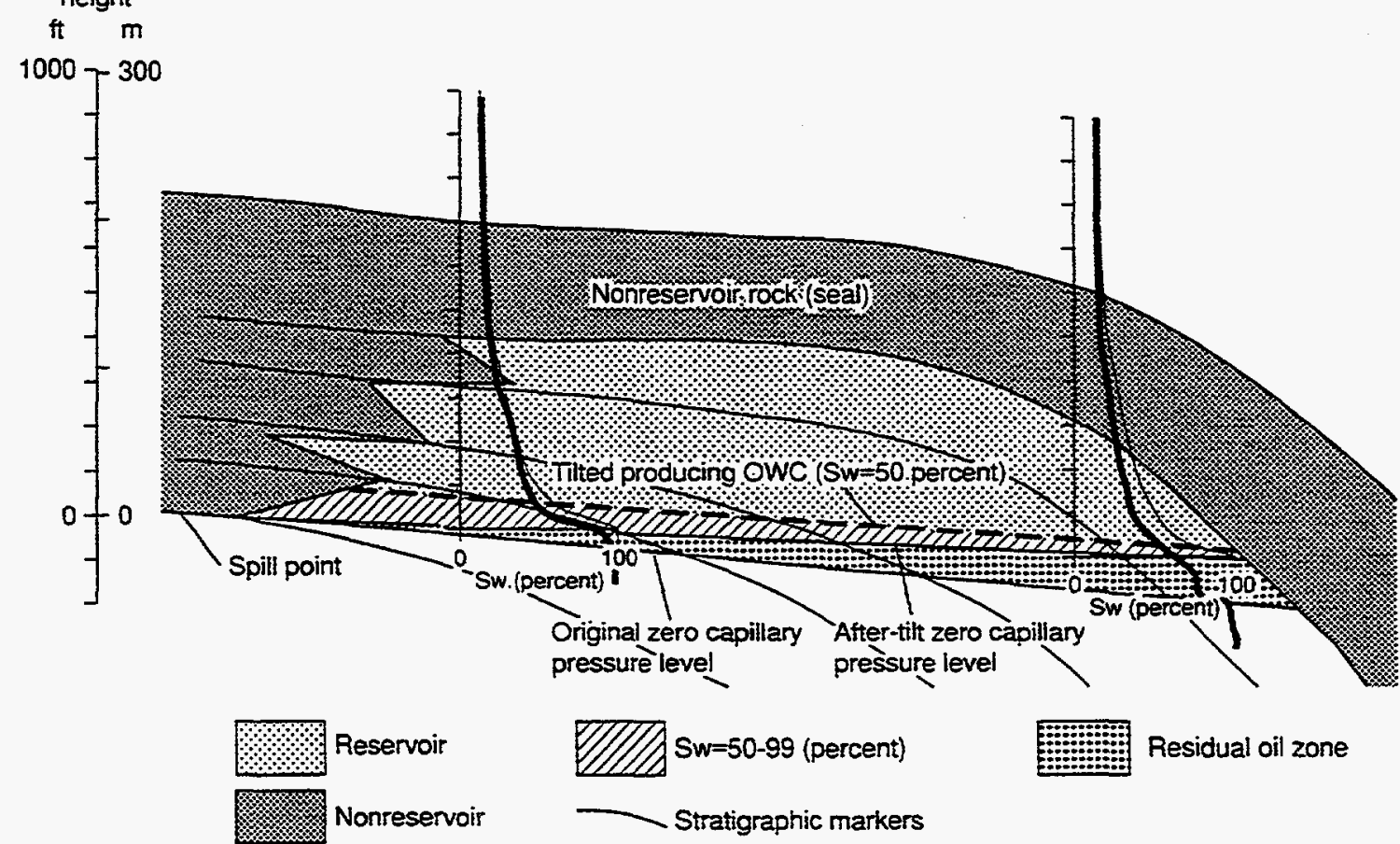

Residual oil zone

QAb5545e

Figure 25. Illustration of the effect of tilting and remigration on saturation profiles resulting from imbibition considerations. (a) Diagram of the original trap showing east and west water saturation profiles for a 10 percent porosity class 2 fabric. (b) Diagram of the trap after tilting, showing a wedge of residual oil and a slightly tilted oil-waer contact (OWC) resulting from the change from drainage to imbibition. 
The tilting model predicts a difference in pre- and post-tilt water levels ranging from 0 on the west to $100 \mathrm{ft}$ or more on the east (the thickness of the residual oil zone) (fig 25). This is illustrated in figure 26 . The impact in the western sector is illustrated by assuming a $20-\mathrm{ft}$ decrease in the reservoir height, a change that alters the saturation profile a small amount. If a zero capillary pressure at $-1850 \mathrm{ft}$ subsea is assumed, the drainage capillary-pressure model approximates the imbibition model. The impact in the eastern sector is illustrated by assuming a $100-\mathrm{ft}$ decrease in reservoir height, a change that alters the saturation profile considerably and results in a 100-ft residual oil zone. In this case, a zero capillary pressure at $-1950 \mathrm{ft}$ subsea must be used in the drainage capillary-pressure model to approximate the effects of imbibition. Saturation values from the capillary-pressure model compare well with the eastern imbibition saturation profile above -1850 subsea (fig. 26). However, below -1850 the saturation model understates the water saturation. Only saturation values above -1850 subsea were used in OOIP calculations.

Figure 25B illustrates the changes that are predicted from the Tertiary tilting. The illustration shows a residual oil zone thinning from east to west, a slightly tilted producing oilwater contact, and lower water saturation in the lower few hundred feet of the reservoir in the east than would be expected from the drainage model.

\section{Rock Fabric Effects}

Although the reservoir is predominantly class 2 , it is known from thin-section examination that both class 1 and class 3 fabrics exist locally. Recent infill wells that appear to have encountered unswept areas of the field, and wells that have penetrated below the $G$ marker, have saturation profiles that suggest class 1 and class 3 as well as class 2 fabrics. To investigate the effect of rock-fabric classes on saturation, profiles were calculated for each class in the Moss Unit 17-22 well and compared with Archie saturation profiles. 
(a)

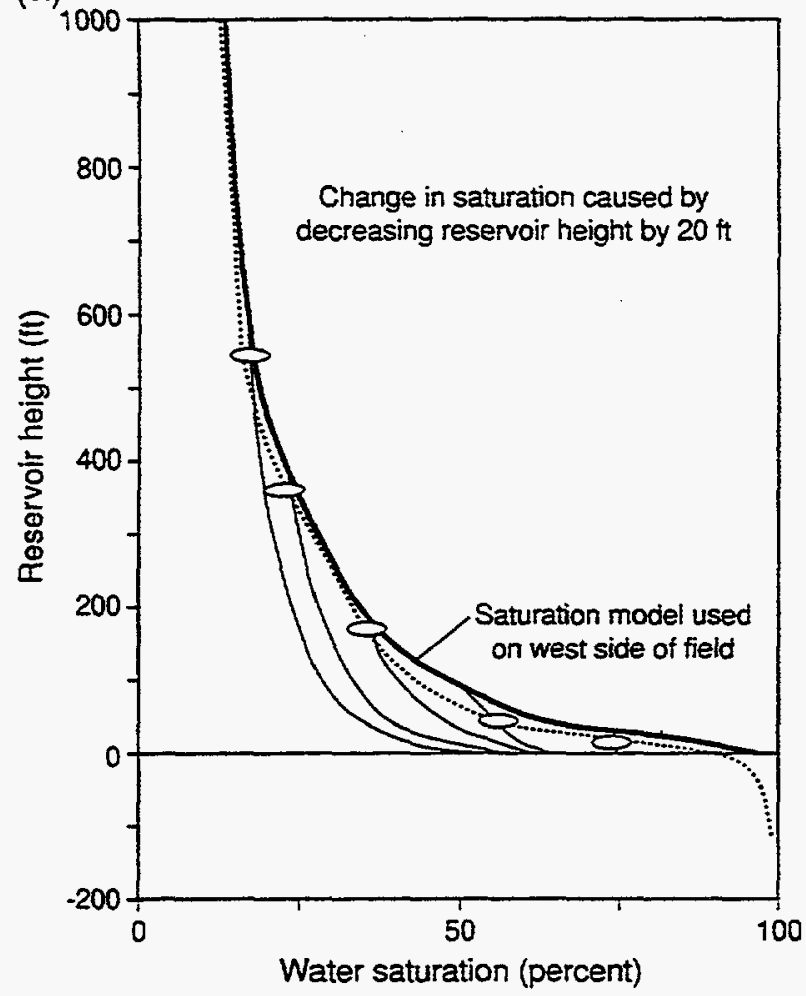

(b)

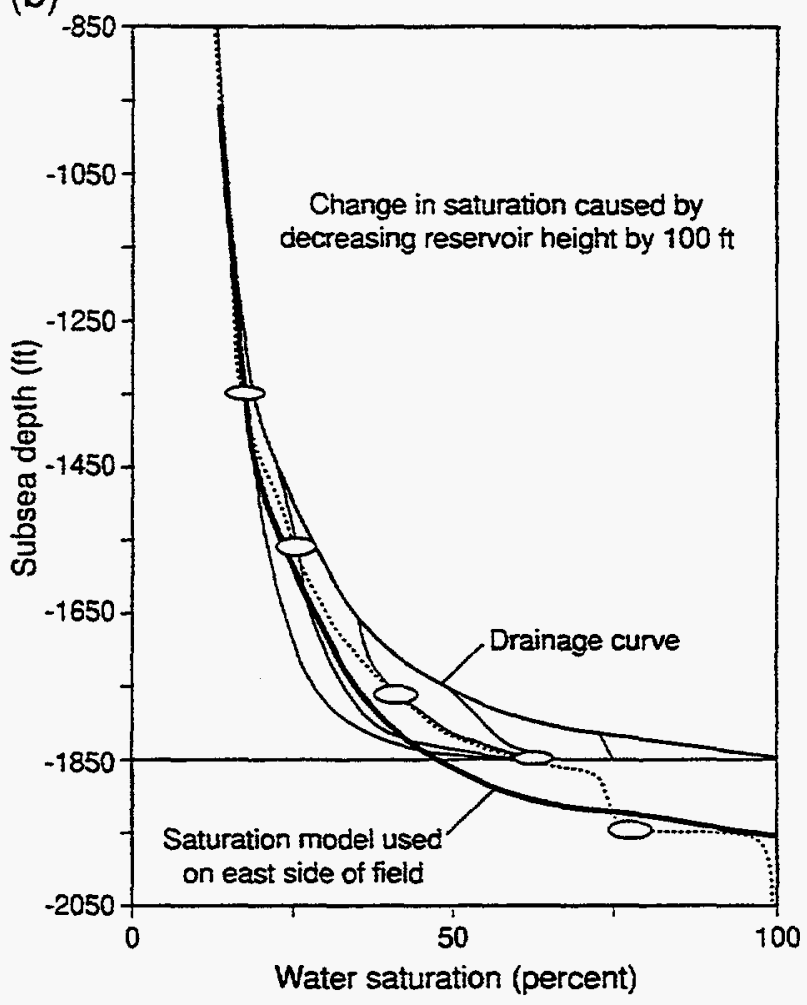

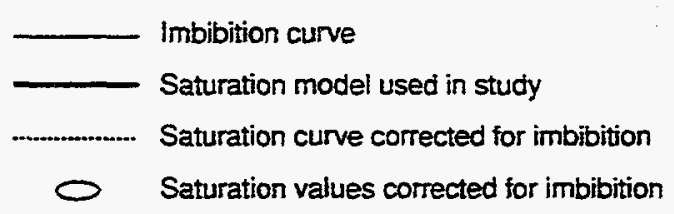

OAb5546C

Figure 26. Comparison of imbibition and drainage-saturation models in the updip (west) and downdip (east) locations using the class 2 capillary-pressure model and 10 percent porosity. Notice the lower $\mathrm{S}_{\mathrm{w}}$ values in the imbibition model. The downdip imbibition curve is approximated by shifting the class 2 model down to a zero capillary pressure depth of -1950 . No change is required in the updip position.

A cross plot of porosity and Archie water saturation from the upper 10-20 ft of the $G$ interval in selected wells illustrates the effect of rock-fabric classes on saturation (fig. 27a). Each petrophysical class has a unique saturation-porosity transform. These transforms are compared with transforms calculated from capillary-pressure models for classes 1,2 , and 3 , assuming a reservoir height of $200 \mathrm{ft}$ above -1950 . A zero capillary-pressure level of -1950 was used because these wells are in the eastern sector of the reservoir. The results (fig. 27b) show a reasonable comparison between the capillary-pressure model and the Archie model. 
(a)

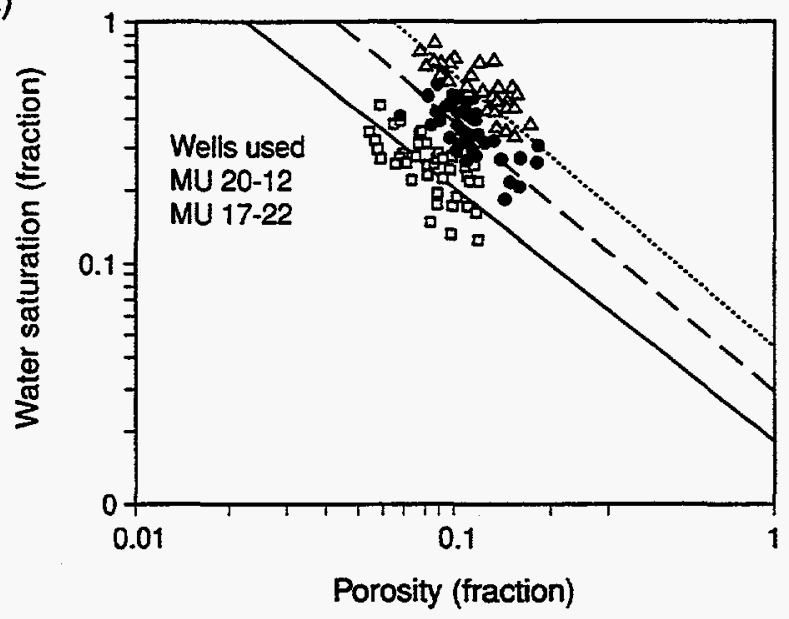

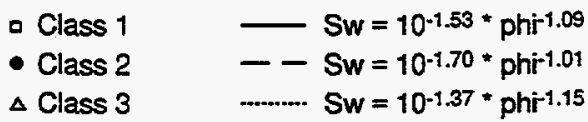

(b)

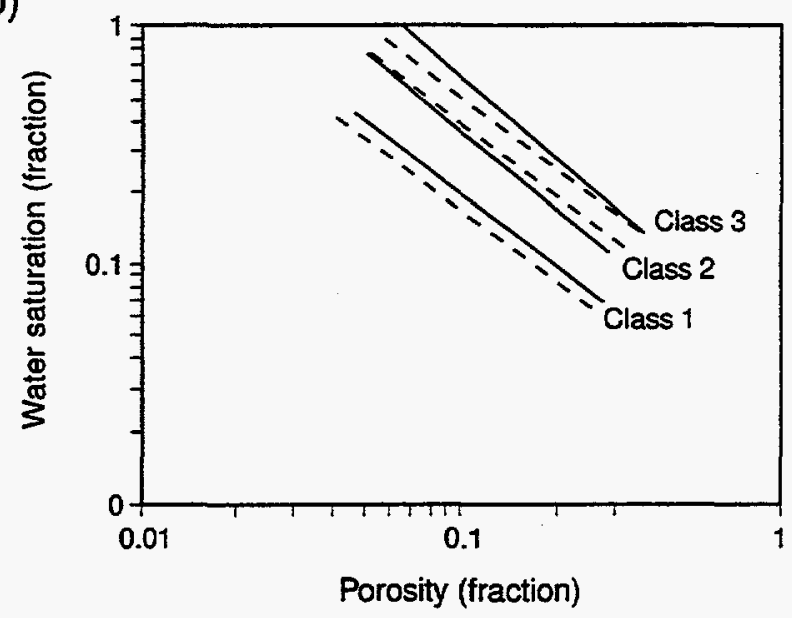

- G interval $\quad---\mathrm{CP}$ at $\mathrm{H}=200(\mathrm{ft})$

QAb5547C

Figure 27. Cross plots of porosity, water saturation, and rock fabric for the $G$ interval. (a) Archie calculated $\mathrm{S}_{\mathrm{w}}$ versus porosity from wireline logs for three rock-fabric classes. Three saturation models are presented for this height above the zero capillary pressure level. (b) A comparison of Archie water saturation values and capillary pressure estimates using a reservoir height of $200 \mathrm{ft}$.

Petrophysical classes can be determined by comparing Archie saturation values with saturation from capillary-pressure models. A depth plot of the three saturation models in the lower portion of Moss Unit 17-22 is shown in figure 28 along with the Archie saturation profile. A comparison of the Archie water saturation with saturation from class 1,2, and 3 capillary- 
Moss Unit 1722

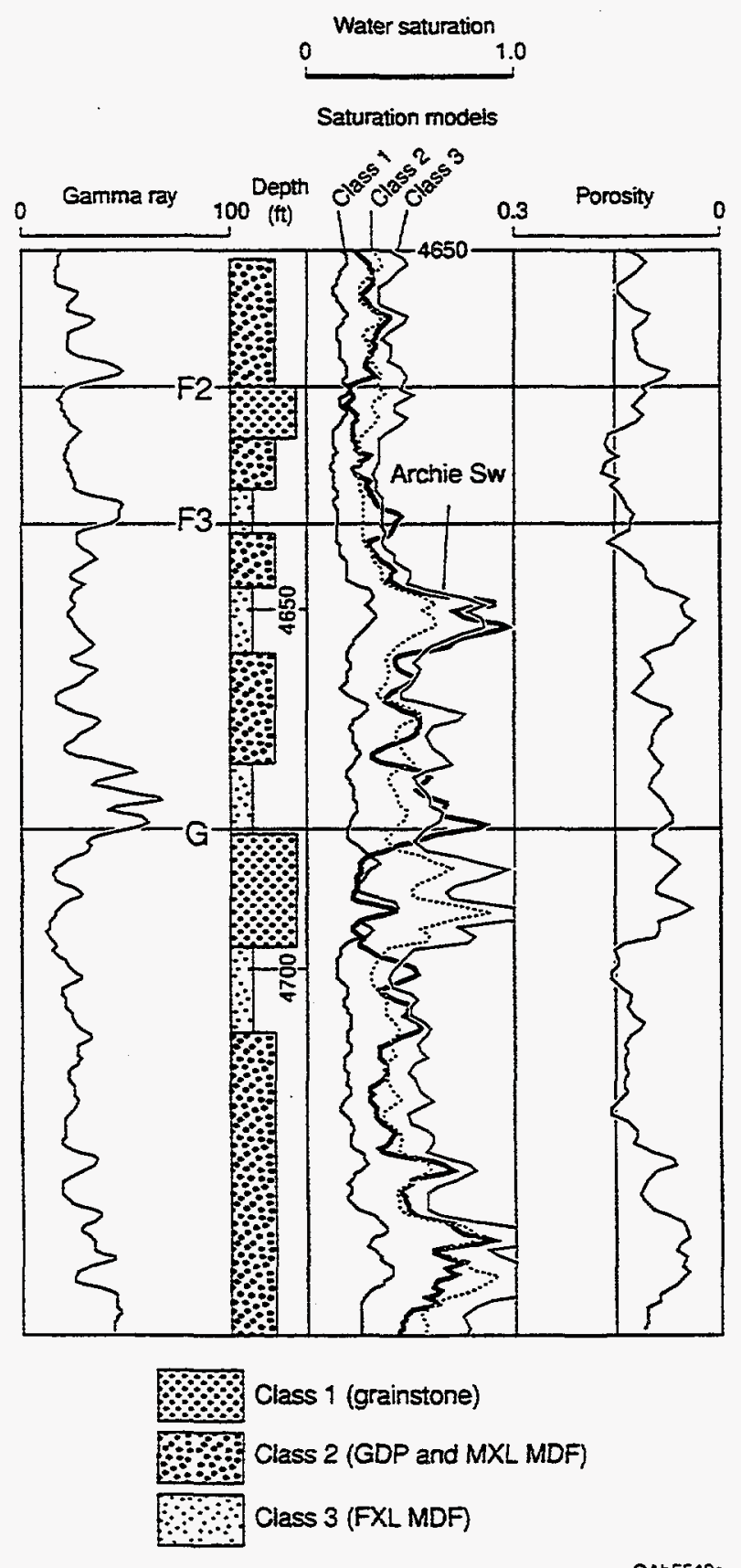

OAb5548c

Figure 28. A portion of Moss Unit 17-22 well illustrating how rock fabric can be interpreted from saturation considerations. Archie saturation values are compared with capillary-pressure saturation profiles for classes 1,2, and 3. Rock-fabric classes are determined by the capillary-pressure profile that most closely matches the Archie saturation values. There are no flooded intervals in this portion of the well. 
pressure models suggests that (1) the F2-F3 cycle has a vertical progression of class 3,2 , and 1 ;

(2) the $G$ interval is capped by class 1 which is underlain by class 3 and then by class 2 ; and

(3) the F3-G cycle alternates between class 2 and 3. Class 1 intervals are probably

dolograinstone, whereas class 2 and 3 intervals probably reflect changes in dolomite crystal size and the amount of intergrain mud.

Identification of Flooded Intervals

Intervals that have been invaded by injected water can be identified by comparing the original $S_{w}$ with current $S_{w}$. Within the oil column and where rock fabric is constant, water saturation decreases as porosity increases in unflooded intervals. Where water-saturation values increase as porosity increases, the interval either has been flooded or has a different rock fabric. As described previously, the study area can be characterized as class 2 rock fabric.

The original $S_{w}$ can be estimated using capillary-pressure models. Current water saturations can be estimated from well logs using the Archie equation. A problem in using the Archie equation is determining the resistivity of formation water $\left(R_{w}\right)$ because of potential flooded intervals. A review of water analyses from the Moss Unit indicates that original water resistivity was $0.08 \mathrm{ohm} / \mathrm{m}$ at $77^{\circ} \mathrm{F}$ and produced floodwater is $0.2 \mathrm{ohm} / \mathrm{m}$ at $77^{\circ} \mathrm{F}$. An $R_{\mathrm{w}}$ of $0.08 \mathrm{ohm} / \mathrm{m}$ was used in initial calculations and $0.2 \mathrm{ohm} / \mathrm{m}$ in intervals that are interpreted to be flooded. Using this method, water saturation in flooded intervals ranges between 50 and 60 percent.

Identifying flooded intervals using this method is illustrated by comparing saturation values from the class 2 capillary-pressure model with Archie saturation values in Moss Unit Well 8-8wr (fig. 29). This well was drilled in 1994 as a replacement well for a water injector (MU8-8w). MU8-8w was originally completed as an oil well in 1965 and converted to a water injector in 1967. The well was never perforated below the F1 marker.

The comparison of the class 2 saturations with the Archie saturations shows that most of the flooded intervals lie above the F1 marker (fig. 29). In the replacement well, a test of this interval swabbed 35 barrels of oil and 164 barrels of water in 24 hours consistent with the interpretation 
Moss Unit 8-8wr

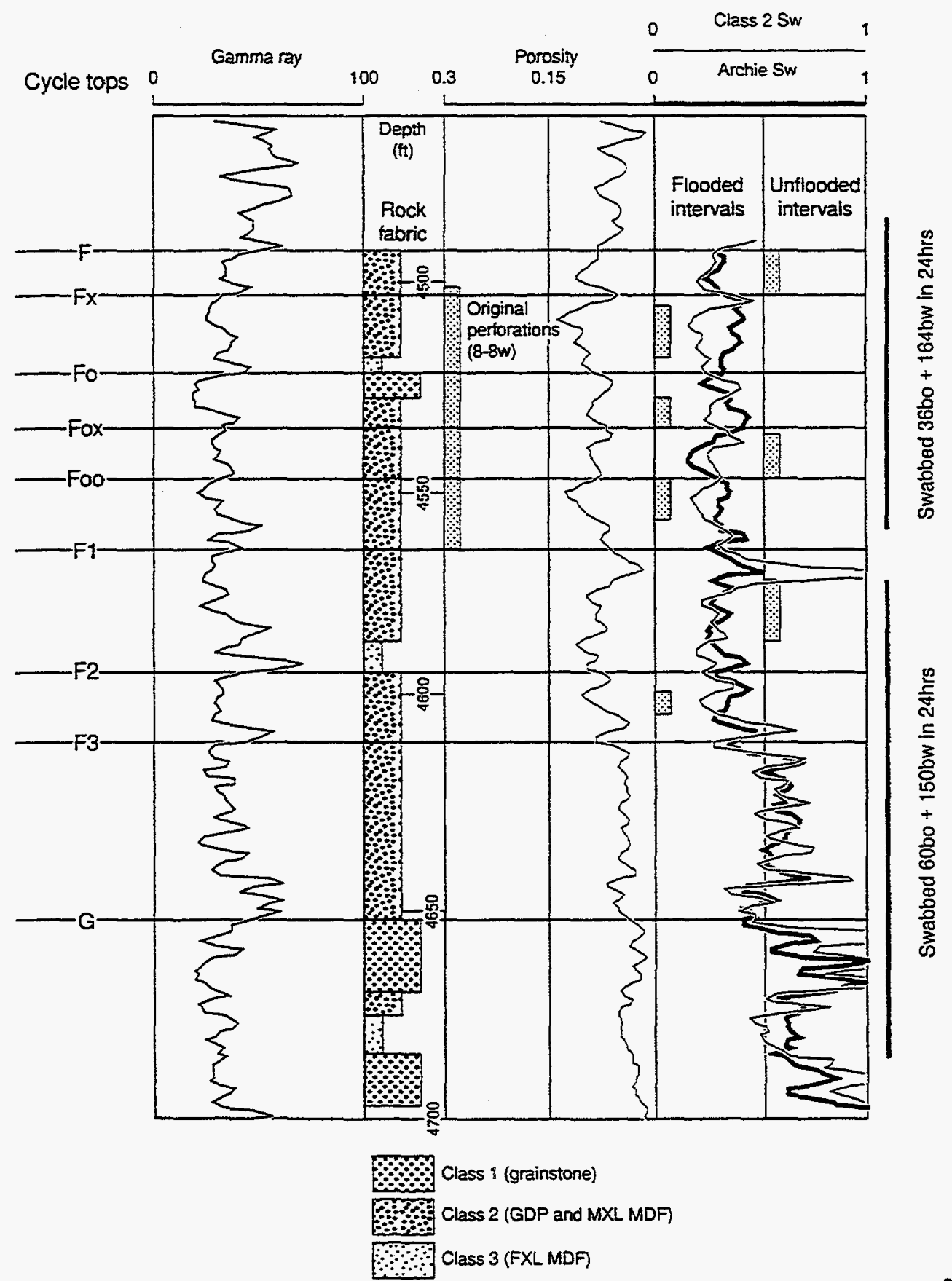

OADS549C

Figure 29. Illustration of flooded and unflooded intervals in the Moss Unit 8-8wr well, a replacement well for the 8-8w water injection well completed in 1965. Flooded intervals are interpreted from the departure of the Archie water saturation values from the capillary-pressure saturation model for class 2. Flooded intervals alternate with unflooded intervals opposite the perforations in well $8-8 \mathrm{w}$. Below the perforations, there is little evidence of floodwater. Oil and water was produced from new perforations below and adjacent to the old perforations. Notice the rock-fabric effects in the $G$ interval. 
that this interval has both flooded as well as unflooded intervals. Below the F1 marker the F1-F2 interval is unflooded. There is a possible flooded zone between F2 and F3, which could also be explained by a change to Class 3 finely crystalline mud-dominated dolostone. The rest of the section has higher than 50 percent $S_{\mathrm{w}}$ because of low porosity and transition zone effects. A test of this interval swabbed 60 barrels of oil and 150 barrels of water in 24 hours, again suggesting unflooded zones. The water is probably not floodwater but water produced from high water saturations below the $\mathrm{G}$ marker. The well was completed from all perforations pumping 19 barrels of oil and 38 barrels of water per day.

\section{Permeability}

Permeability is a function of pore size and pore-size distribution, which is a function of particle size and sorting (grains and crystals), interparticle porosity, and the amount and type of vuggy porosity. Thin-section study has shown that most of the reservoir in the study area is composed of grain-dominated dolopackstone, medium crystalline mud-dominated dolostone, and poorly sorted medium-fine crystalline mud-dominated dolostone. These fabrics can be grouped in the petrophysical class 2 and characterized by a single porosity-permeability transform. An example is shown in figure 30, where core data from Moss Unit 6-16 is compared with the generic class 2 transform from Lucia (1995). This transform is used to calculate permeability in acoustic groups 1 and 2 (fig. 15):

$$
k=\left(2.04 \times 10^{6}\right)\left(\phi^{6.38}\right) \text {. }
$$

In downdip areas the permeability is enhanced by the presence of vugs and microfractures formed by the dissolution of anhydrite. This area is identified by acoustic group 3 (fig. 15). The effect is illustrated in figure 31 by a plot of core porosity and permeability values from wells located in acoustic group 3, and the equation used to calculate permeability in group 3 is presented below. As can be seen in figure 31, this equation results in permeability values five times higher than those calculated from the class 2 equation:

$$
k=\left(2.384 \times 10^{6}\right)\left(\phi^{5.762}\right) \text {. }
$$




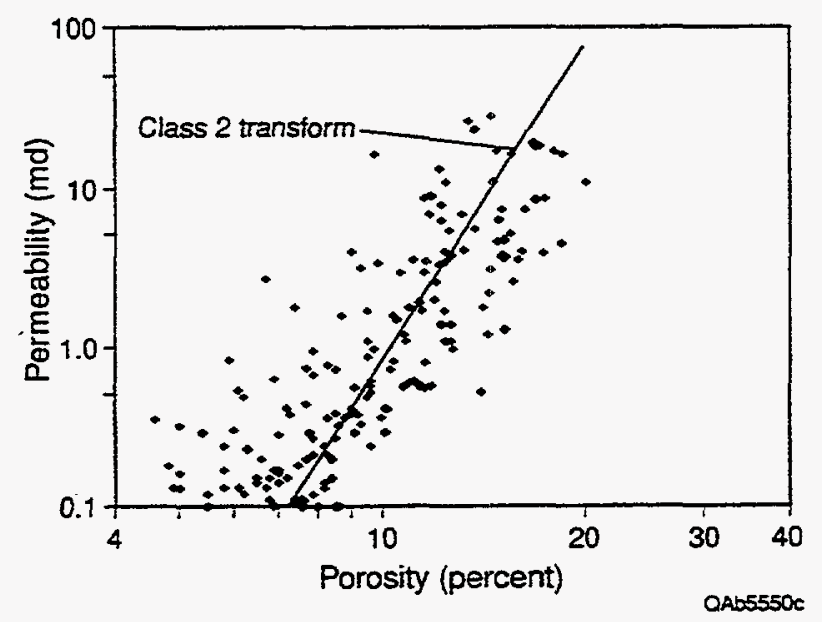

Figure 30. Porosity and permeability data from Moss Unit 6-16 core analysis data compared with the generic class 2 porositypermeability transform of Lucia (1995).

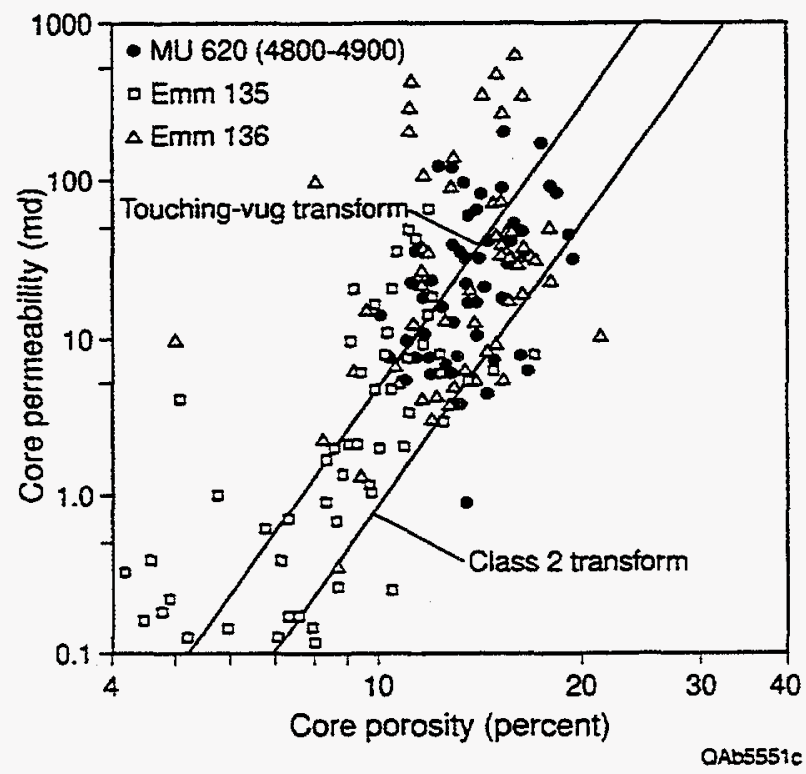

Figure 31. Porosity-permeability cross plot of core data from the interval 4800-4900 in Moss Unit 6-20, Emmons Unit 135, and Emmons Unit 136. The permeability transform for the touching-vug, dissolved anhydrite fabric is five times higher than the class 2 transform. 
Although most of the reservoir in the study area can be characterized by class 2, core and log analysis suggest textural differences in the G-H interval. In this interval, grainstone-capped cycles are typical (Ruppel and Bebout, 1996), and rock-fabric/saturation relationships discussed previously suggest the presence of intergranular pore space in dolograinstones (class 1) and fine crystalline mud-dominated dolostone (class 3 ) as well as in grain-dominated dolopackstones and medium crystalline mud-dominated dolostone (class 2 ). When permeability is calculated using rock-fabric-specific permeability transforms, the permeability profile differs markedly from that calculated using the class. 2 transform alone (fig. 32). Permeability values differ by an order of magnitude between the three classes.

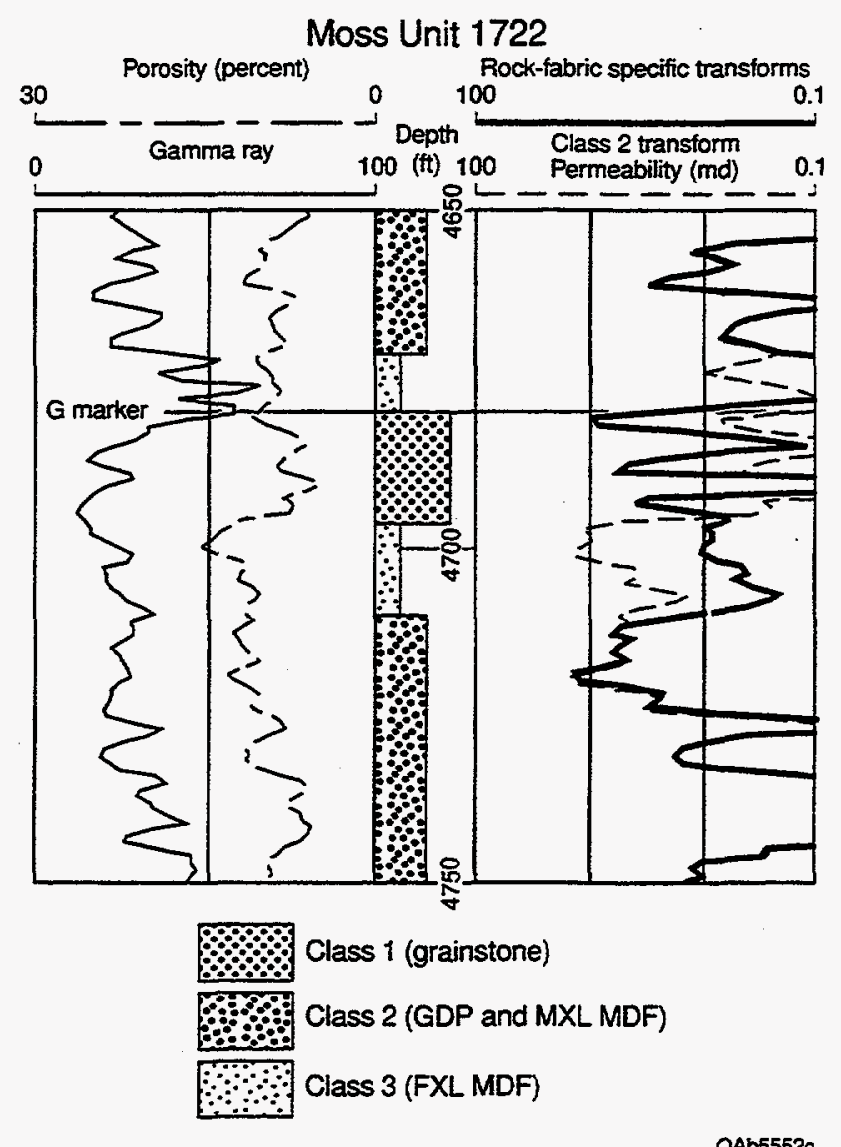

Figure 32. Depth-permeability plot comparing the permeability profile using the class 2 transform only with a profile that incorporates three rock-fabric-specific transforms. Notice the increase in estimated permeability in class 1 intervals and the decrease in class 3 intervals. 
A kh map of the reservoir (Top E marker to -1850 subsea) was constructed using values calculated from wireline logs (fig. 33). Only wells drilled subsequently to the original development wells were used because the original development wells were all completed with nitroglycerin, and log suites are inadequate for permeability calculations. The map shows an area of high $\mathrm{kh}$ that coincides with the area of highest production (fig. 2). Kh decreases easterly because of the intersection with the OWC. The kh also decreases updip in a westerly direction as a result of decreasing reservoir quality. One major difference between the $\mathrm{kh}$ and production maps is that the northeasterly trend of high $\mathrm{kh}$ in the northern part of the field is not matched by. high production.

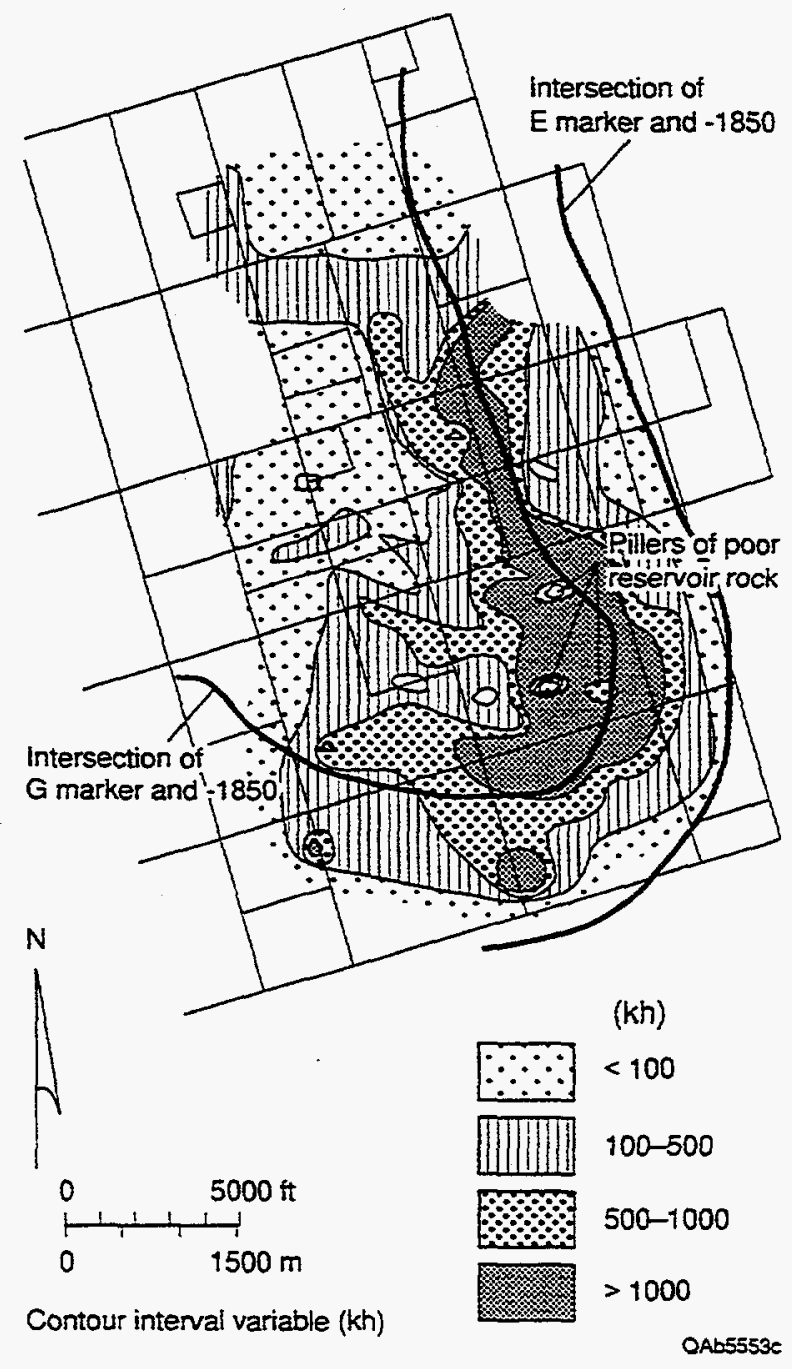

Figure 33. Isopach map of permeability-feet $(\mathrm{kh})$ in the reservoir interval ( $E$ to -1850$)$ of the study area. Notice the indicated pillars in the Emmons Unit. 


\section{PERMEABILITY HETEROGENEITY}

Permeability of carbonate rocks varies at several different scales (Kerans and others, 1994). Outcrop and core studies have shown that permeability can vary several orders of magnitude at the inch to foot scale within one single rock-fabric unit. This variability does not appear to be directional, with vertical permeability only slightly less than horizontal permeability, and the variability has poor spatial correlation.

Cores from the South Cowden field show the presence of a patchy distribution of porosity on the scale of inches, perhaps related to burrows produced in the rock by burrowing organisms (Ruppel and Bebout, 1996). This texture is referred to as a chaotic texture by some operators. Detailed analysis by Phillips Petroleum Company shows that the average porosity and permeability in the dense matrix is 10 percent and $22 \mathrm{md}$, compared with 21 percent and $211 \mathrm{md}$ in the porous patches. A similar feature has been reported from the San Andres reservoir, Penwell field, by Major and others (1990), where the dense matrix has a permeability of about $1 \mathrm{md}$ and the porous patches $10 \mathrm{md}$. In both cases, the permeability of the porous patches is an order of magnitude higher than that of the surrounding rock.

In addition to the small-scale variability, outcrop and subsurface studies have shown that permeability can vary (1) within rock-fabric facies on the scale of thousands of feet, and (2) at the scale of rock-fabric facies. Studies have also shown that, whereas there can be significant differences in the permeability characteristics of rock-fabric facies, lateral changes between rockfabric facies are gradational and vertical changes are commonly abrupt.

These observations, however, are based on a strong depositional-textural control on permeability, and, in the South Cowden field, diagenesis in the form of dolomitization and sulfate alteration and dissolution has overprinted much of the depositional control. Dolomitization has converted much of the reservoir to petrophysical class 2 by increasing the particle size of the mud-dominated fabrics to between 20 and 100 microns, thereby reducing the degree of stratigraphic control on reservoir development. Additionally, sulfate dissolution has formed a touching-vug fabric and has removed even more of the stratigraphic control in the eastern sector of the field. 
High-frequency cycles are basic mapping units and rock-fabric facies are basic flow units for quantification in carbonate-ramp reservoirs. In the South Cowden field, however, dolomitization has overprinted depositional textures by increasing particle size, leaving porosity and not rock fabric as the primary attribute in defining flow units. In the area of acoustic group 1 , the porosity-defined flow units tend to be conformable with HFC.

This is illustrated in figure 34 . There is an abrupt permeability terminate to the west. Within the $G$ interval, permeability bodies are stratigraphic and discontinuous. Cycle F3-G is low permeability throughout-most of the field and divides the reservoir. HFC's F2-F3, F1-F2, Fx-Fo, and F-Fx are permeable, and there is a discontinuous permeability interval that straddles the Foo marker. Barriers to flow are found at the Fx marker, as a cemented grainstone at the top of cycle Fo-Fox, at top of F1 (a major flood-back atop of HFS 3). The cycles in 4B are typically low permeability in the western sector.

Detailed permeability maps were constructed for each HFC in a 640-acre area composed of parts of sections $5,6,7$, and 8 . Cycles F2-F3, F1-F2, Fx-Fo, and F-Fx are illustrated in figure 35. Kh maps of cycle F2-F3 and F1-F2 show a northwest-southeast band of high permeability and several low permeability areas. The kh map of cycle Fx-Fo shows no areas of low permeability and a dramatic increase in kh on the eastern edge that coincides with the area of dissolved anhydrite and touch-vug fabrics.

Within the area of anhydrite dissolution, cycle stratigraphy is less useful in characterizing the permeability structure. All cycles below the $F$ marker, the top of HFS $4 a$, tend to be permeable with permeability profiles characteristically cross-cutting cycle boundaries (fig. 36). Vertical barriers to flow are thin and laterally discontinuous on the scale of hundreds of feet rather than complete cycles as in the western sector. Cycle F3-G changes from tight in the western sector to permeable in the east. Permeability above $10 \mathrm{md}$ is more common than in the western sector, and high permeability appears to be laterally continuous for thousands of feet in cycles Fo-Fx and F2-F3. The cycles in HFS $4 \mathrm{~b}$ have discontinuous permeability probably produced by dissolution of pore-filling anhydrite in dolograinstones. An example is shown in 


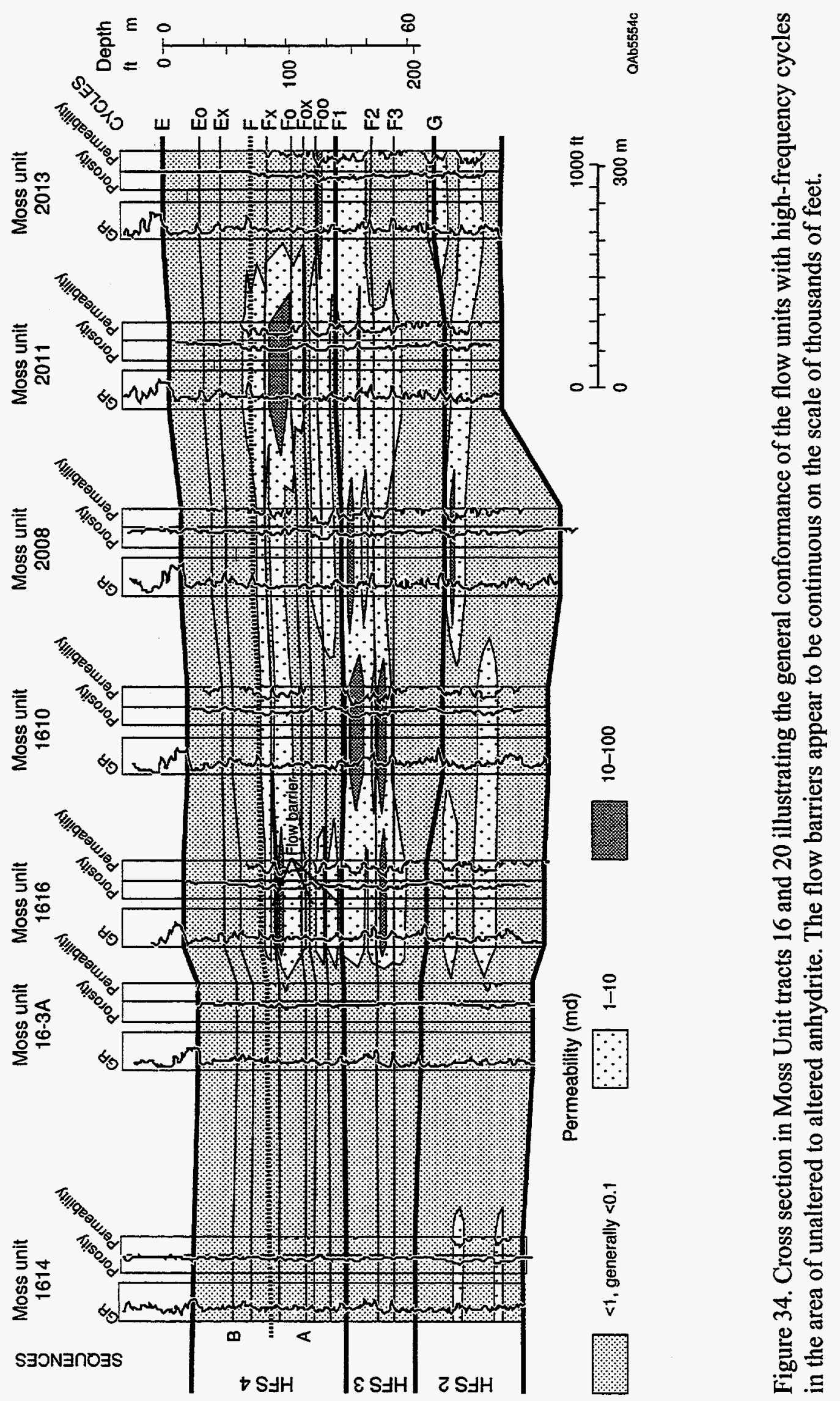



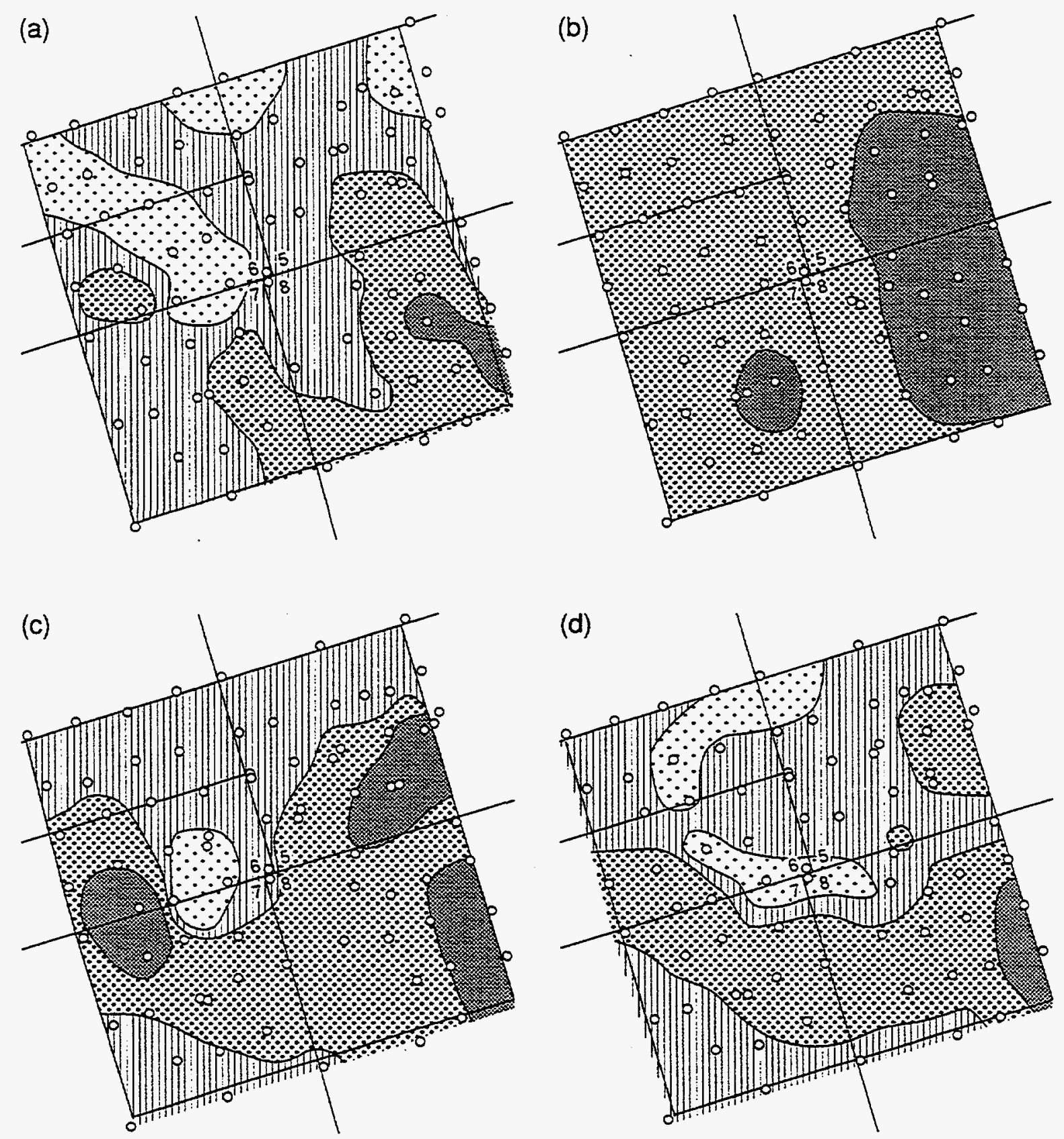

(kh)

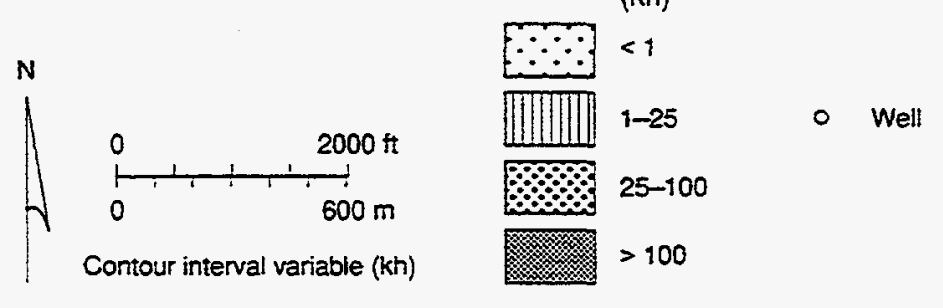

OAb5555C

Figure 35. Detailed $\mathrm{Kh}$ maps of four high-frequency cycles in the altered and unaltered areas. Notice (1) scattered areas of little permeability, and (2) the increase in kh at the eastern edge, particularly in cycle Fx-Fo. The increase is due to the dissolution of anhydrite. 


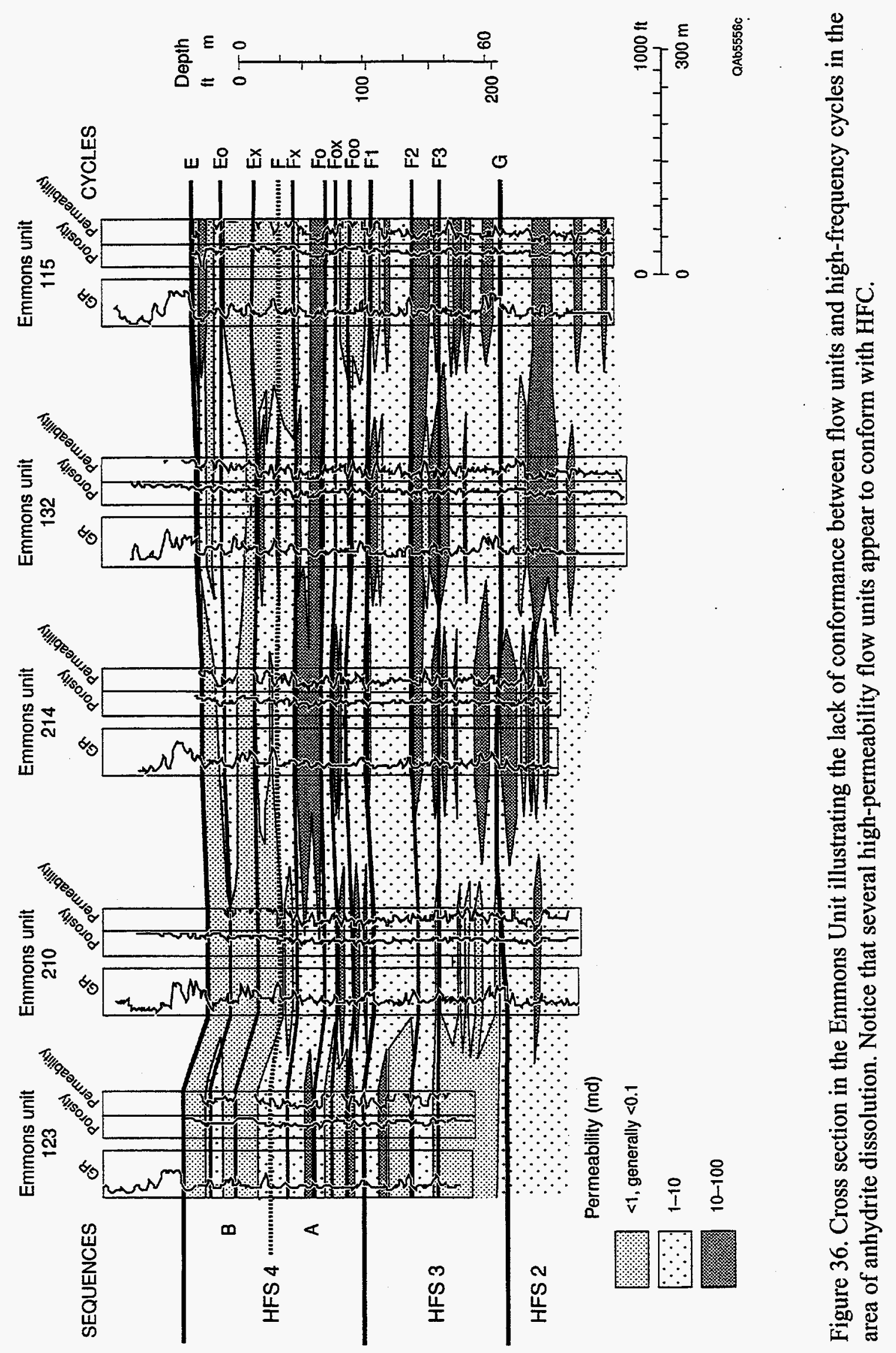


figure 37 where a local porous and permeable body is located in HFC Ex-Eo, which is normally composed of dense anhydrite-plugged grainstone-capped cycles.

A unique feature of the anhydrite dissolution area is the presence of pillars of low permeability. These pillars are believed to be areas of altered anhydrite that are left behind by the advancing dissolution front. In the Emmons Unit, at least three pillars have been penetrated (fig. 38), and have lateral dimensions of hundreds of feet. A detailed image of the most closely controlled pillar penetrated by Emmons 121 shows an irregularly shaped body (fig. 38) of low permeability. The size, shape, and number of these pillars is unknown, but it is suspected that many more pillars exist in the reservoir than can be mapped by well control.

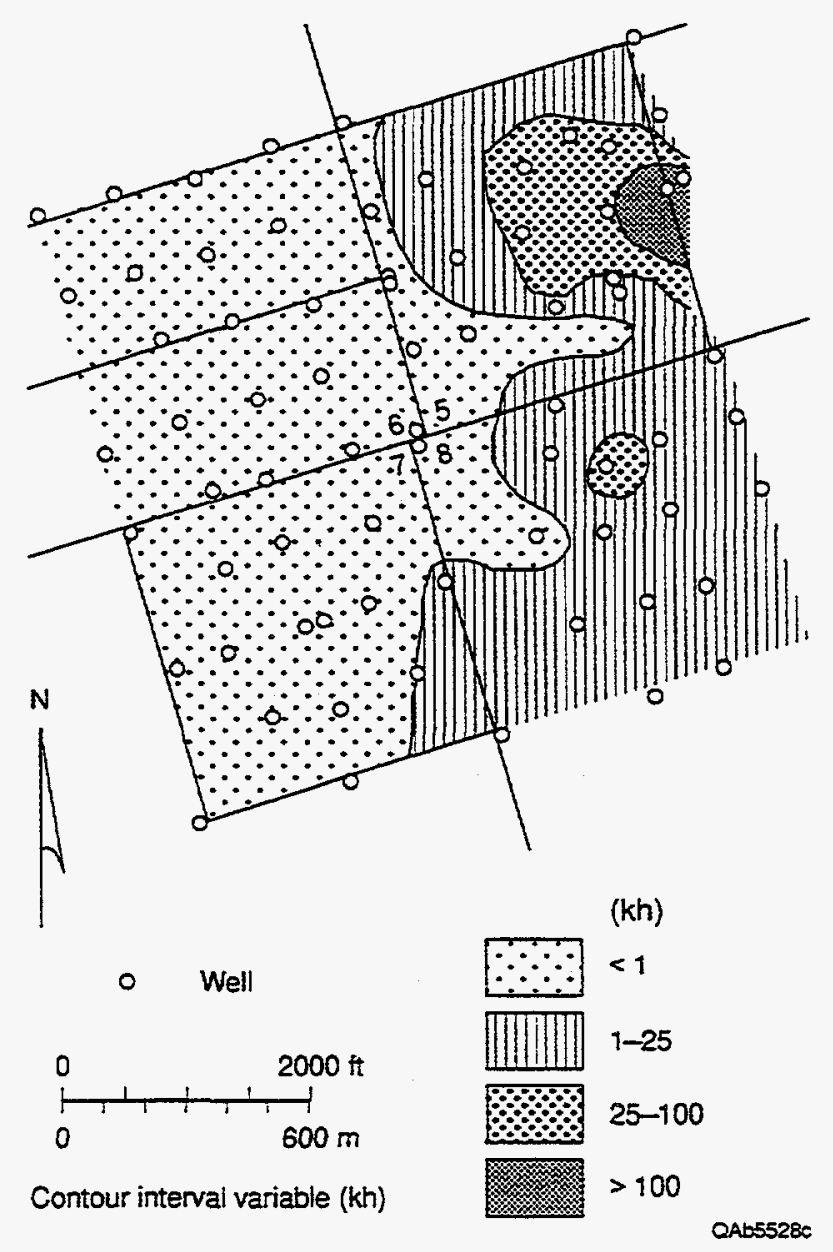

Figure 37. Isopach map of permeability-feet $(\mathrm{kh})$ values from cycle Ex-Eo in HFS $4 \mathrm{~b}$ showing local permeability development interpreted to result from dissolution of pore-filling anhydrite in a grainstone body. 
(a)

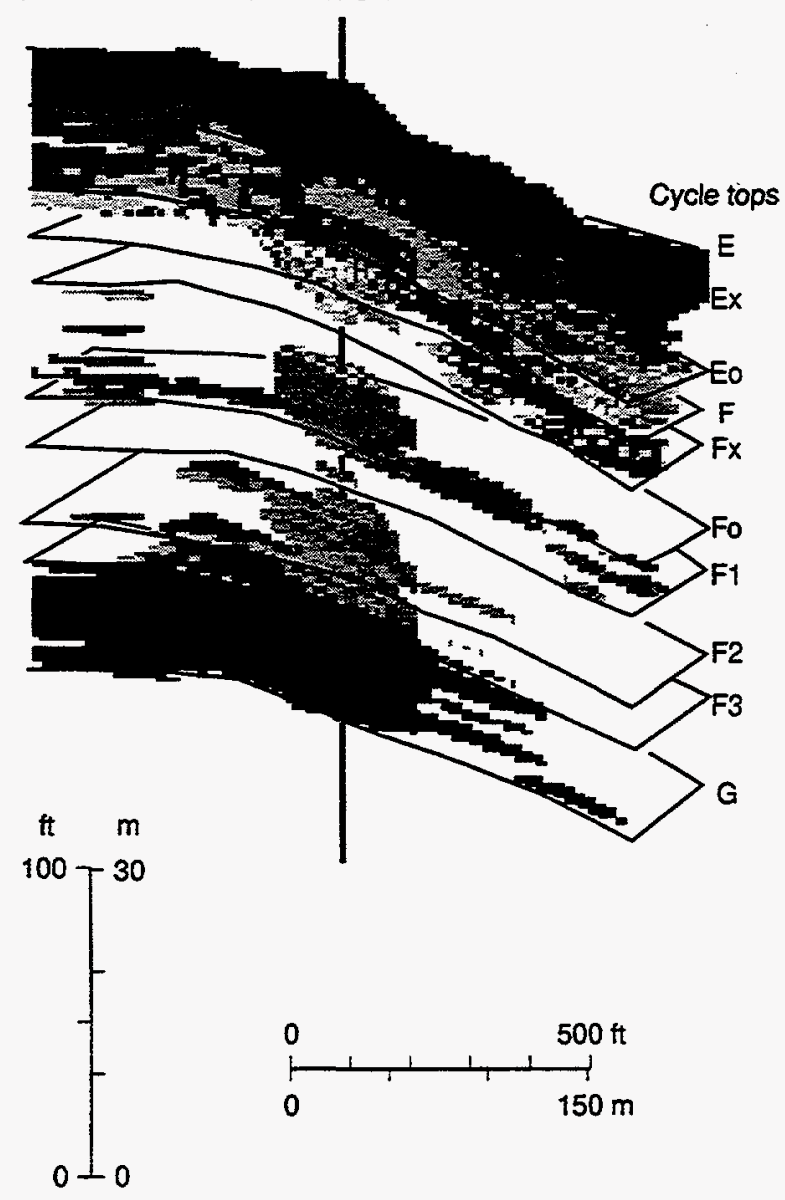

(b)

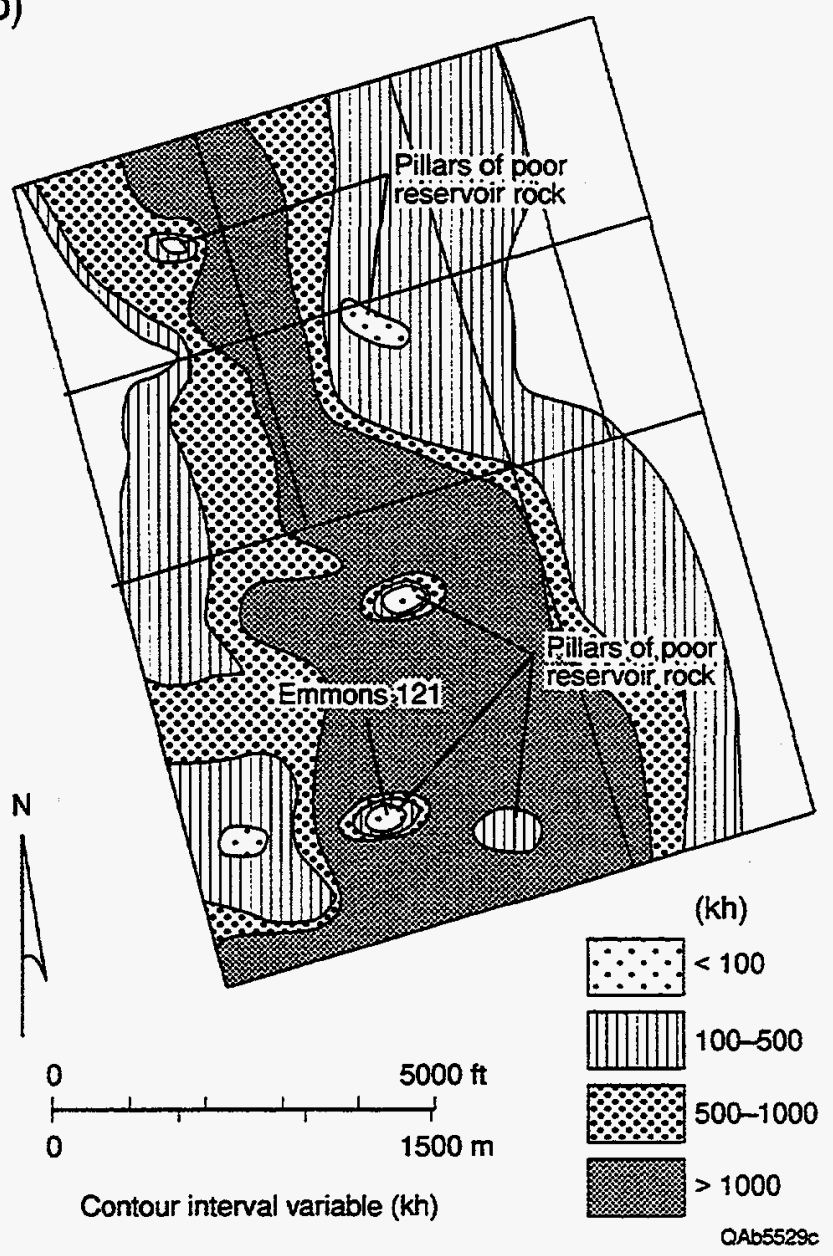

Figure 38. Illustrations of altered anhydrite facies within the dissolved anhydrite facies. (a) Threedimensional image of nonreservoir rock $(\mathrm{k}<0.1 \mathrm{md})$ in the dissolved anhydrite area of the Emmons Unit showing the geometry of a residual pillar of altered anhydrite. (b) A map of known pillars within the dissolved anhydrite facies.

\section{LOCATION OF REMAINING MOBILE OIL}

Recovery from the South Cowden reservoir is estimated to be about 21 percent of the original oil in place, and residual oil to water flooding is estimated at 35 percent of the OOIP. The remaining 44 percent oil is mobile oil that can be recovered if contacted by the waterflood. Because the waterflood front is time dependent and Archie saturation values are only a snapshot in time, accurate flow simulations are required to map the location of remaining oil at any specific time. However, insight into the location of the remaining mobile oil is gained by 
comparing the estimated original oil saturations based on capillary-pressure curves with oil saturations based on Archie-saturation calculations. These procedures bave been discussed previousiy. Infill wells drilled after water flooding show (1) no indication of floodwater (MU8-12 is an example); (2) selected cycles contain floodwater (MU 8-8wT is an example); or (3) all or most of the cycles contain floodwater (Emmons 216 is an example). These results indicate that the remaining oil is located in bypassed cycles and in unflooded areas of the field between injectors.

Most recently (1996), four infill wells were drilled in the first half of 1996 on the lease line between the Moss Unit and the Emmons Unit. Two wells encounter what appear to be unflooded areas and two encounter a mix of flooded and unflooded cycles. In the Moss Unit 20-12, the interval from F to F1 appears flooded and the lower intervals unflooded (fig. 39). The Moss Unit 20-13 encountered an unflooded area. In this well the F-Foo interval has low permeability. Offset injectors are not perforated below the F1 marker, suggesting little cross flow of floodwater into lower cycles. Many injectors in the field are not perforated below the Fl marker, suggesting that much of the remaining mobile oil is located in the lower half of the reservoir.

\section{CONCLUSIONS}

Diagenesis in the South Cowden reservoir has bad a significant effect on permeability patterns. The field can be characterized best by dividing it into three diagenetic areas on the basis of the anhydrite diagenesis, although there is a gradual change from complete anhydrite dissolution to anhydrite alteration. In the western sector, overdolomitization, compaction, and anhydritization have occluded much of the porosity and effectively eliminated much of the permeability. In reservoir intervals, mud-dominated limestone fabrics have been replaced by medium crystalline dolomite fabrics, resulting in increased particle size and loss of petrophysical distinction between grain- and mud-dominated fabrics. Therefore, a single porosity-permeability transform (petrophysical class 2) and a single saturation model based on capillary pressure and wireline log data can be used to characterize the reservoir. The geologic framework of highfrequency cycles is the most useful architecture in the construction of reservoir models because the reservoir intervals conform to high-frequency cycles. 


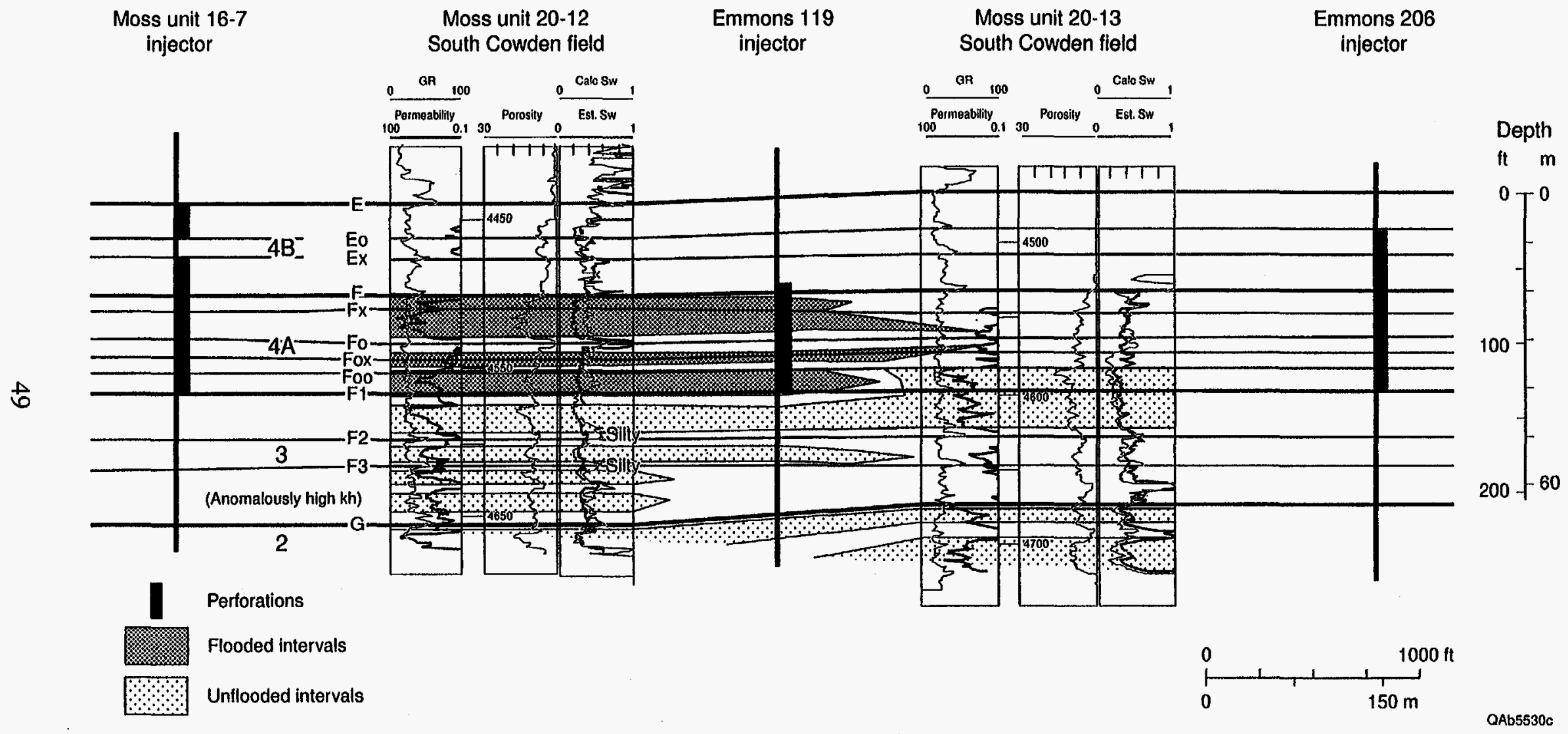

Figure 39. Cross section of recent infill wells showing (1) flooded zones are adjacent to injection intervals (Moss Unit 20-12), and (2) unflooded zones are below injection depths and where upper pay zones are not well developed (Moss Unit 20-13). 
In the eastern sector, dissolution of anhydrite has created a touching-vug pore geometry by removal of anhydrite from nodules, fusumolds, and microfractures. A more optimistic porositypermeability transform characterizes this sector because of the touching vugs, but capillary pressure data suggest that the saturation model used in the western sector can be used. Highfrequency cycles are only moderately useful in constructing a reservoir model. The dissolution area is characterized by (1) fewer and laterally less continuous vertical flow barriers, (2) rapid lateral changes in the form of pillars of undissolved anhydrite, and (3) localized bodies of permeable grainstones.

Between the anhydrite and dissolved anhydrite areas is an area of altered anhydrite, which is characterized by higher porosity and permeability values and separate-vug as well as intercrystal and intergrain pore types. The class 2 porosity-permeability transform and the same saturation model characterizes this area.

Three diagenetic fabrics have been calibrated to acoustic-porosity transforms, and, together with core data, the distribution of the anhydrite diagenetic fabrics has been mapped, revealing a west-to-east increase in anhydrite diagenesis. This suggests that fluids undersaturated with respect to anhydrite moved from east to west probably in response to compaction of Midland Basin sediments.

In wells with only acoustic logs, rock-fabric-specific porosity transforms are used to calculate porosity. Many wells have either case-hole or open-hole logs, and these are calibrated to core data. The most accurate porosity values are calculated from wells with neutron and density logs or a sidewall neutron log.

Insight into the location of remaining mobile oil is gained by comparing original water saturation values with Archie saturation values in infill wells. Reasonable estimates of the original water saturation can be made from an analysis of capillary-pressure curves. Although the water saturation values from wireline logs are questionable because of the uncertainty in $R_{w}$, a comparison of the two water saturations can indicate intervals that have been invaded by floodwater. Analysis of these data suggests that unflooded oil remains (1) in unflooded areas between 
injectors, and (2) as bypassed oil in specific high-frequency cycles. Because most of the injectors are not perforated in the lower reservoir, most of the bypassed oil appears to be in this part of the reservoir.

\section{REFERENCES}

Grant, C. W., Goggin, D. J., and Harris P. M., 1994, Outcrop analog for cyclic-shelf reservoirs, San Andres Formation of Permian Basin: stratigraphic framework, permeability distribution, geostatistics, and fluid-flow modeling: American Association of Petroleum Geologists Bulletin, v. 78, n. 1, p. $1-22$.

Kerans, C., Lucia, F. J., Senger, R. K., 1994, Integrated characterization of carbonate ramp reservoirs using Permian San Andres Formation outcrop analogs: American Association of Petroleum Geologists Bulletin, v. 78, no. 2, p. 181-216.

Lucia, F. J., 1995: Rock-fabric/petrophysical classification of carbonate pore space for reservoir characterization: American Association of Petroleum Geologists Bulletin, v. 79, no. 9, p. $1275-1300$.

Lucia, F. J., Kerans, C., Wang, F. P., 1995, Fluid-flow characterization of dolomitized carbonate ramp reservoirs: San Andres Formation (Permian) of Seminole field, and Algerita Escarpment, Permian Basin, Texas and New Mexico; in Stoude, E. L., and Harris, P. M., eds., Hydrocarbon Reservoir Characterization: SEPM Short Course No. 34, p. 129 154.

Major, R. P., Vander Stoep, G. W., and Holtz, M. H., 1990, Delineation of unrecovered mobile oil in a mature dolomite reservoir: East Penwell San Andres Unit, University Lands, West Texas: Bureau of Economic Geology, The Univeristy of Texas at Austin, Report of Investigations No. $194,52 \mathrm{p}$.

Ruppel, S. C., and Bebout, D. G., 1996, Effects of stratal architecture and diagenesis on reservoir development in the Grayburg Formation: South Cowden field, Ector County, Texas: The University of Texas at Austin, Bureau of Economic Geology, annual report prepared for U.S. Department of Energy, Assistant Secretary for Fossil Energy, under contract no. DE-AC2293BC14895, $80 \mathrm{p}$. 
